\title{
Article \\ Experimental Study on Manned/Unmanned Thermal Environment in Radar Electronic Shelter Based on Different Air Supply Conditions
}

\author{
Jue $\mathrm{Qu}{ }^{1,2}$, Hao Guo ${ }^{2}$, Hongjun Xue ${ }^{1, *}$, Sina Dang ${ }^{2}$ and Yingchun Chen ${ }^{1}$ \\ 1 School of Aeronautics, Northwestern Polytechnical University, Xi'an 710072, China; qujue402@sina.com (J.Q.); \\ xueyvshahe@126.com (Y.C.) \\ 2 School of Air and Missile Defense, Air Force Engineering University, Xi'an 710051, China; \\ 1j17792957583@126.com (H.G.); dsnsw123@126.com (S.D.) \\ * Correspondence: xuehj@nwpu.edu.cn
}

check for updates

Citation: Qu, J.; Guo, H.; Xue, H.; Dang, S.; Chen, Y. Experimental Study on Manned/Unmanned Thermal Environment in Radar Electronic Shelter Based on Different Air Supply Conditions. Energies 2022, 15, 1277. https://doi.org/10.3390/ en15041277

Academic Editors: Małgorzata Basińska and Katarzyna Ratajczak

Received: 1 January 2022

Accepted: 1 February 2022

Published: 10 February 2022

Publisher's Note: MDPI stays neutral with regard to jurisdictional claims in published maps and institutional affiliations.

Copyright: (C) 2022 by the authors. Licensee MDPI, Basel, Switzerland. This article is an open access article distributed under the terms and conditions of the Creative Commons Attribution (CC BY) license (https:// creativecommons.org/licenses/by/ $4.0 /)$.

\begin{abstract}
Studies on the thermal environment of the electronic radar shelter have been mainly focused on the simulation of the unmanned thermal environment, and there have been few studies on experiments in the thermal environment. Additionally, a comparative study of the experimental results from manned and unmanned shelters has been missing. In this paper, we experimented in thermal environments of manned/unmanned shelter under different air supply conditions. The experiment was divided into cooled, ventilated, and heated trials analyzing three aspects: (1) The average temperature distributions of walls, air inlet points, air outlet points, and surfaces were measured over time under different conditions in an unmanned shelter. The temperature distribution curve was fitted into the function. (2) Based on different working conditions, the temperature distribution experiments were carried out in three different areas for subjects wearing short or long clothing respectively. (3) The wind speed was measured at each measuring point in the air supply pipeline under different working conditions. The wind speed distribution was detected on the setting surfaces. The experimental results show that: (1) The air does not gradually tend to steady state with the time, and under different conditions, the air temperature obviously differs. (2) The clothing selection, air supply conditions, and locations of measuring points have significant influences on human body temperature distribution and left-right difference. (3) The mixing of the thermal plume caused by the vertical temperature difference of the human body and the jet generated by the mechanical air supply will reduce the wind speed of the airflow in the cabin, the adsorption of the jet to the bulkhead, and the stability of the airflow. The experimental data can provide the initial and boundary conditions for the simulation of the shelter. The results can provide a reference for the study of fluid control methods, the setting of thermal boundary conditions, and the simulation of the influence of thermal plumes on the airflow distribution. The experimental study in this paper has filled in the blanks regarding experimental study in electronic radar shelters. It has important research value and practical significance.
\end{abstract}

Keywords: electronic radar shelter; thermal environment; manned and unmanned; air distribution; temperature and wind speed

\section{Introduction}

Electronic radar shelters (shelters), as the core equipment for operators performing operational tasks, are where operators can carry out human-computer interaction tasks [1]. When faced with complex and urgent tasks, operators need to monitor the interface and work in a shelter for a long time. The thermal environment of the shelter has a direct impact on the physiological state and mental health of operators, thereby affecting their efficiency. A electronic radar shelter is generally a closed space with many electronic products and densely-packed personnel. To keep the temperature within a reasonable 
range is necessary to ensure the comfort of the operators and proper functioning of the electronic equipment [2].

Existing studies on thermal environment mainly focus on vehicle cabins, aircraft cockpits, spacecraft cabins [3-5], and rooms in buildings [6]. A thermal environment is often studied through a combination of simulations and experiments [7].

Regarding simulations, Fujita et al. [8] established a car cockpit model using CFD, and simulated the internal thermal environment of a car under different air supply conditions by using the standard turbulence model. CFD simulations and machine learning algorithm were combined to predict the thermal comfort of passengers in Ware and Khalighi's paper [9]. Three machine learning algorithms, stochastic gradient descent linear regression, random forest, and artificial neural network, were applied to the simulated data to predict the equivalent uniform temperature for passengers (EHT) and the average air temperature distribution. Zhang and Chen [10] adopted the renormalization group (RNG) two-equation turbulence model in CFD to simulate the airflow organization in an aircraft cockpit under a mixed air distribution system, and proved that the RNG two-equation turbulence model could be applied to the simulation of the airflow organization in an aircraft cockpit. In order to solve the complex heat transfer problem of coupling air flow, solid conduction, and radiation in a pressurized chamber, Lu, Huang, and Fan [11] established a numerical model of flow and heat transfer in the pressure chamber of a manned spacecraft. Awolesi et al. [12] established a numerical model of flow and heat transfer in the pressure chamber of a manned spacecraft. It was concluded that the RANS turbulence model could be applied to the simulation of airflow structure in a workshop, and the applicability of CFD to simulations of buildings' thermal environments was proved. Such simulations are mainly carried out via CFD, and the correctness of the boundary conditions, initial conditions, and results of such simulations need to be verified by experiments.

In terms of experiments, Zhang et al. [13] conducted an experimental study on the air flow field and temperature distribution in an automobile cockpit under thermal environmental conditions. The occupant's body was divided into nine segments, and the skin temperature of each segment was continuously monitored. The results showed that the air temperature inside the cabin was highly uneven. The occupant's position had a significant influence on the occupant's thermal response. Applying skin temperature to the design and control of HVAC system parameters was beneficial to improving thermal comfort and reducing energy consumption. Qi et al. [14] conducted experimental studies on the dynamic thermal environment of an automobile cabin and the local thermal sensations of front and rear occupants at different driving states in summer with air conditioning running. The results showed that the air temperature, occupant skin temperature, and local thermal sensations were all affected by occupant position, body part, and driving state. In the study of Cao [15-19], a heated dummy was selected to conduct an experimental study on the thermal environment in an airplane cabin. PIV and infrared thermal imaging equipment were used to analyze the changes in cabin temperature and wind speed. It was pointed out that the thermal plume produced by the human body has a big influence on the air distribution in a cabin.

Through an experimental study on the thermal environment under microgravity or simulated microgravity, the changes in autonomous and behavioral temperature regulation caused by the effect of weightlessness in space flight and ground simulations were obtained in Yang's paper [20]. The paper put forward some measures to protect astronauts' temperature regulation, such as exercise training, simulating natural ventilation, and encouraging drinking.

On the mutual verification of experiments and simulations, Mao et al. [21] measured the air and wall temperature and the heat flux of different closed surfaces during refrigeration and heating in an automobile cabin. Then a transient numerical simulation of an electric vehicle cabin was carried out to analyze the air flow and temperature changes in the cabin under the same conditions as the experiment. The numerical model accurately predicted the temperature variations with an error rate of less than $10 \%$ from the experimental 
data. Aboosaidi, Warifield, and Choudhury [22] used the $k-\varepsilon$ two-equation turbulence model and mixed turbulence model to simulate the airflow structure of two aircraft cabins under different air supply conditions. The comparison between the simulation results and the experimental results showed that the two turbulence models could accurately predict the air distribution in the cabin, and the CFD technology could be applied to the simulation of air distribution in the cockpit. Meng [23] proposed a design for an air temperature and humidity control system to be used in the cabins of manned spacecraft based on the combination of a single-phase fluid loop and cabin ventilation. Based on the experimental and analytical results, a simplified semi-active cabin air temperature control model was established. The cabin's heat loss characteristics were obtained through ground tests. The cabin's heat loss had a linear relationship with cabin air temperature within a limited range. Flight tests verified the effectiveness of the cabin air temperature control model. Han et al. [24] proposed a new control method for indoor temperature, which relies on collecting human skin temperature through infrared imaging, estimating the current thermal sensations of the human bodies, and predicting the future thermal sensations of human body. They verified the effectiveness of the control method through experiments.

Through the existing research and analysis, it can be seen that experimental research is a necessary means for studying the thermal environments of cabins. Experiments can not only obtain the real cabin air distribution and human body temperature distribution, but also provide initial conditions and boundary conditions for simulation results, and verify the correctness of simulation models. Therefore, experimental research plays a very important role in the study of cabins' thermal environments.

The existing experimental research on thermal environments has mainly focused on three aspects: indoor thermal environment parameters, including the wind speed and the temperature changes in airflow; human thermal comfort; the temperature distribution of a human in the thermal environment.

The main problems with previous research are as follows:

1. Indoor thermal environments' parameters have been studied, mainly the parameters of airflow distribution and equipment temperature. However, the measurement results could not give quantitative descriptions and were not extensible. Only according to the temperature distribution under experimental conditions can the initial conditions, boundary conditions, and guidance for simulations be given.

2. The temperature difference between the upper and lower portions of the human body is the most detail that has been considered in the research on human thermal comfort. The temperature difference between left and right sides of the human body and the differences caused by different clothes were not considered. The influence of the human body on airflow distribution in thermal environment was not analyzed.

3. In the experiments where the thermal environment was affected by human temperature, heated dummies normally used. However, these heated dummies do not have the real temperature regulation abilities of the human body. Using a heated dummy to study the airflow distribution in the cockpit certainly was not accurate.

4. There are few studies on the thermal environments of vehicle-mounted shelters, such as electronic radar shelters, and the only studies that do exist were mainly focused on simulating the airflow organization of simplified shelters without considering the temperature changes of the operators' bodies [25-30]. There are no detailed experimental data to provide initial and boundary conditions for a simulation model, or to verify the simulation results of a shelter model. The electronic radar shelter is a sealed space, and its air distribution is seriously uneven and asymmetrical, making its thermal environment quite different from a general indoor setting. The existing experimental data on indoor thermal environments cannot be applied to the simulation verification of a shelter by means of migration.

Based on the above problems, we performed manned/unmanned experiments with an electronic radar shelter. In the experimental study of thermal environment parameters, the temperature distribution functions under different air supply conditions were 
fitted. This function can not only express the temperature variation law under the set working conditions, but also supply the temperature distribution function for measuring points under other set temperature conditions and different air supply conditions. In the simulation process, the function given in the experiment was used to verify whether the simulation results under different initial conditions in a certain temperature range would be correct. In terms of human body temperature distribution, this paper measured the human body temperature distribution up and down, left and right, and with long and short clothing. We analyzed the factors affecting the temperature distribution, and obtained the human body temperature distributions under the different conditions. In terms of the influence of human body temperature on the thermal environment, we used a real human for experiments. This study confirmed the effectiveness of previous studies, but more clearly revealed the impact of the change in airflow distribution around the human body on the wind speed distribution, making the experimental results more accurate. On this basis, through the analysis of the air distribution in the ventilation duct under different air supply conditions, we found that the wind speed under refrigeration is large, and we can explain the reason. It has certain guiding significance. Therefore, this experimental research on a shelter was particularly important.

\section{Experiments and Methods}

\subsection{Experimental Conditions of the Shelter}

\subsubsection{The Shelter's Geometry}

The shelter size's was $4.360 \mathrm{~m}$ (length) $\times 2.370 \mathrm{~m}$ (width) $\times 1.890$ (height). The front was transparent glass (as observed in the experiment), and the other five sides were enclosed by iron sheets. There were two LED lights on the ceiling of the shelter. The shelter included two areas: an air supply duct and the shelter space. The air supply pipeline was composed of seven groups, a group having 18 openings, and a total of 168 air supply vents. The vents were divided into upper pipeline air supply, middle pipeline air supply, and lower pipeline air supply. Five groups of worktables were arranged in the space of the cabin. The display control stations were located directly below the air supply pipe and closed to the wall with air inlet and outlet. The air inlet was located on the right side of the pipe, and the air outlet was directly below the air inlet, as shown in Figure 1a. On this basis, three operating stations were prepared, and three operators were selected per group of subjects. The positions of operating stations and operators are shown in Figure 1b. The number and specific sizes of devices are shown in Table 1; and the name, size, monitoring method, number, and type of each device are given. The size given in the Table 1 is the design size.

Table 1. Structural dimensions of all equipment in the cabin.

\begin{tabular}{|c|c|c|c|c|}
\hline Name & Size (m) & Number & Monitoring Mode (Number of Points) & Equipment \\
\hline Inlet pipe & $\begin{array}{c}\text { X: } 4.360 \text { (length) } \times 0.200 \times 0.300 \\
\text { Y: } 2.370 \times 0.200 \times 0.300\end{array}$ & 1 & Points $(7 \times 1)$ & \multirow{2}{*}{ Pipe wind meter } \\
\hline Air supply outlet & R: 0.630 & 126 & Open or Close & \\
\hline Ceiling & 4.360 (length) $\times 2.370$ (width) & 1 & Points $(5 \times 1)$ & \multirow{9}{*}{ Temperature sensor } \\
\hline Lights & $0.630 \times 0.286$ & 2 & Points $(5 \times 2)$ & \\
\hline Display control station & $1.600 \times 0.400 \times 0.600$ & 5 & Points $(7 \times 5)$ & \\
\hline Inlet & $0.290 \times 0.080$ & 1 & Points $(3 \times 1)$ & \\
\hline Outlet & $0.330 \times 0.290$ & 1 & Points $(5 \times 1)$ & \\
\hline Glass Wall & $4.36 \times 1.89$ & 1 & Points $(5 \times 1)$ & \\
\hline Wall & $\begin{array}{c}\text { Left/Right: } 2.370 \times 1.890 \\
\text { Back: } 4.360 \times 1.890\end{array}$ & 3 & Points $(5 \times 3)$ & \\
\hline Floor & 4.360 (length) $\times 2.370$ (width) & 1 & Points $(5 \times 1)$ & \\
\hline Display interface & $0.800 \times 0.600$ & 10 & Points $(5 \times 10)$ & \\
\hline Human body & H: $1.700 \sim 1.850$ & 3 & Surfaces $(5 \times 1)$ & \multirow{2}{*}{ PIV Measuring wind speed } \\
\hline chairs & $0.477 \times 0.477 \times 0.800$ & 3 & Surfaces $(5 \times 1)$ & \\
\hline
\end{tabular}




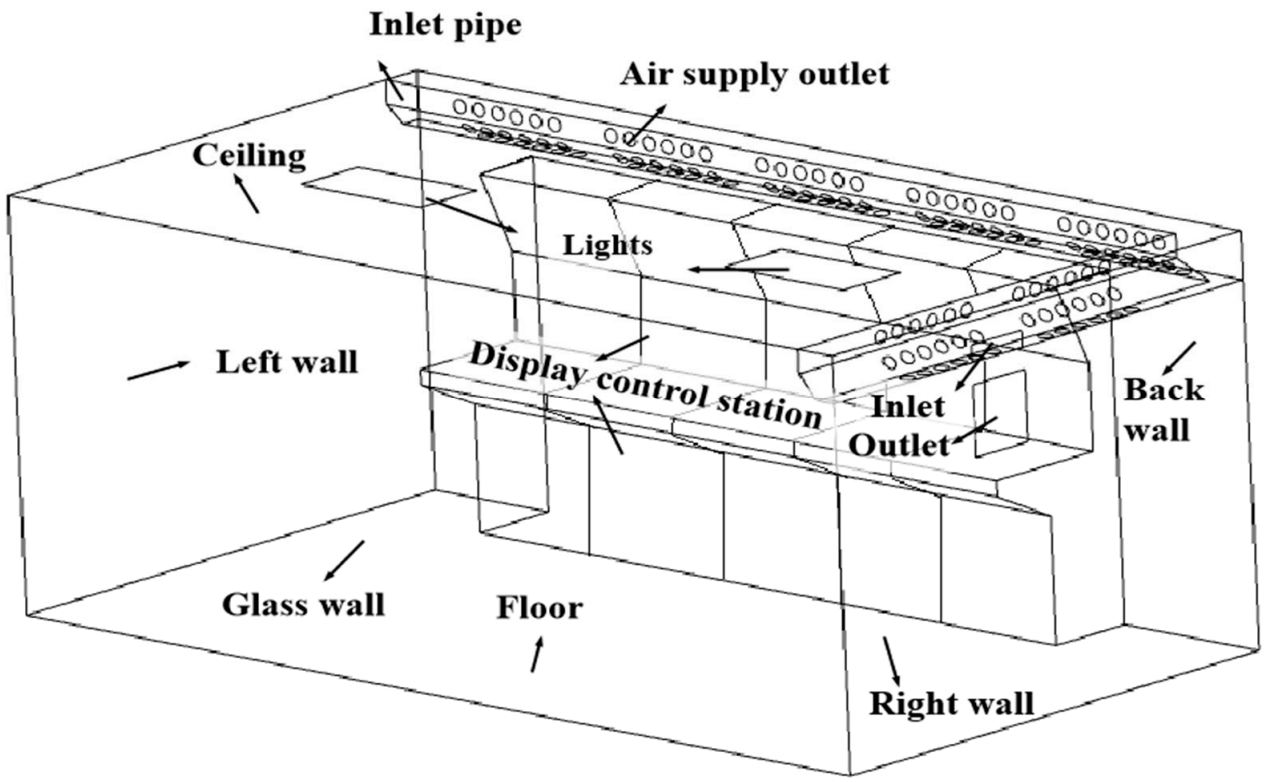

(a)

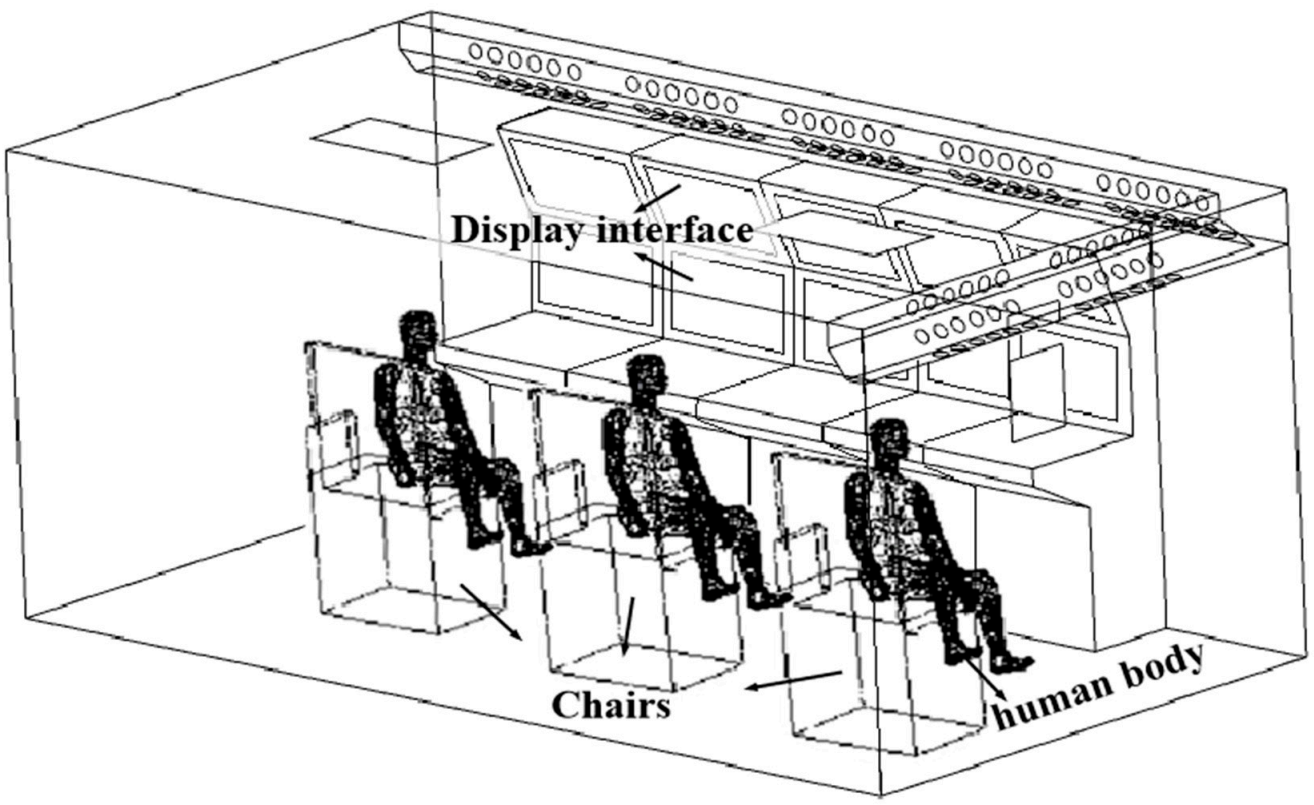

(b)

Figure 1. Geometric model of the cabin. (a) Square cabin geometry and layout. (b) Working stations and number of subjects.

In this paper, geometric sketches, detailed dimensions, and the coordinates of each piece of equipment in the shelter are provided. A three-dimensional cartesian coordinate system was established with the lower left corner of the shelter as the origin. The coordinate system was established with the length of the shelter as the x-axis, width as the y-axis, and height as the z-axis.

1. The letters corresponding to cabin geometry are shown in Figure 2, and the corresponding coordinates of each letter are shown in Table 2. 


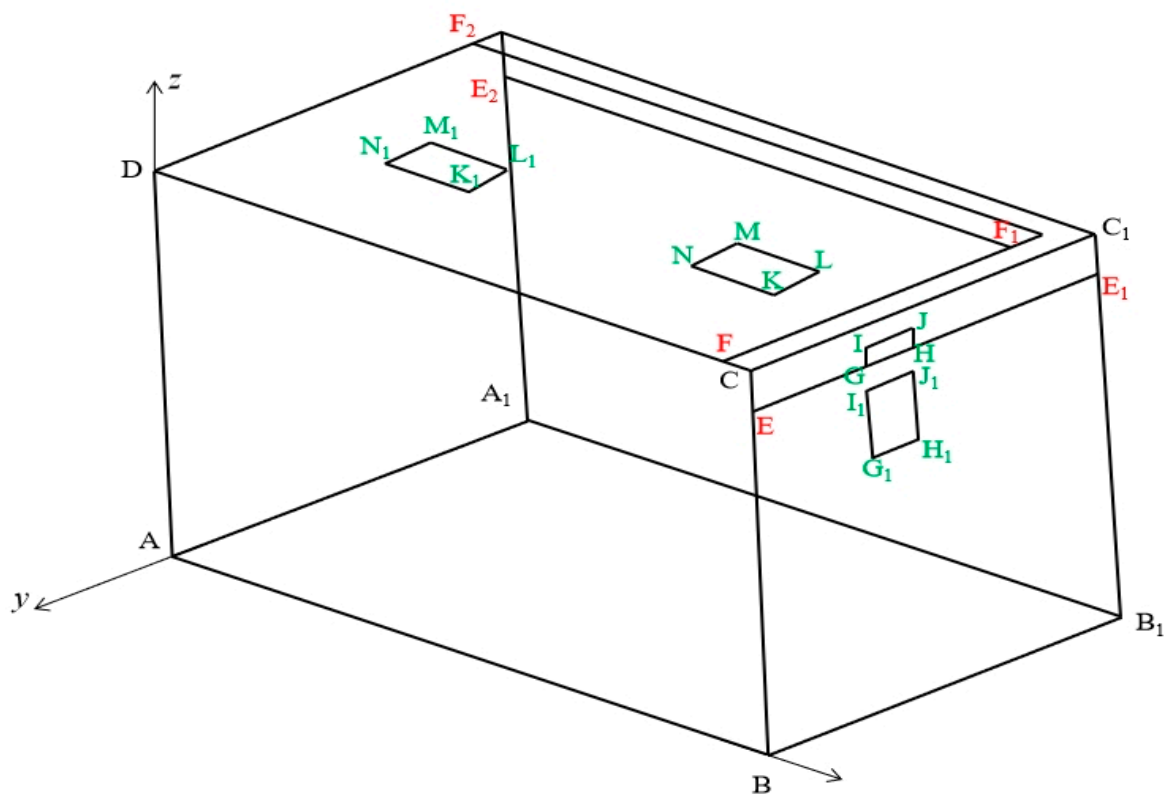

Figure 2. The letters corresponding to cabin geometry.

Table 2. The corresponding coordinates of each letter in cabin geometry.

\begin{tabular}{llll}
\hline & \multicolumn{3}{c}{ The Position of Letters $(\mathbf{x}, \mathbf{y}, \mathbf{z})$} \\
\hline $\mathrm{A}(0.0000,0.0000,0.0000)$ & $\mathrm{B}(4.3612,0.0000,0.0000)$ & $\mathrm{C}(4.3612,0.0000,1.8902)$ & $\mathrm{D}(0.0000,0.0000,1.8902)$ \\
$\mathrm{A}_{1}(0.0000,-2.3711,0.000)$ & $\mathrm{B}_{1}(4.3612,-2.3711,0.0000)$ & $\mathrm{C}_{1}(4.3612,-2.3711,1.8902)$ & $\mathrm{D}_{1}(0.0000,-2.3711,1.8902)$ \\
$\mathrm{E}(4.3612,0.0000,1.5921)$ & $\mathrm{E}_{1}(4.3612,-2.3711,1.5921)$ & $\mathrm{E}_{2}(0.0000,-2.3711,1.5921)$ & \\
$\mathrm{F}(4.1612,0.0000,1.8902)$ & $\mathrm{F}_{1}(4.1612,-2.1711,1.8902)$ & $\mathrm{F}_{2}(0.0000,-2.1711,1.8902)$ & \\
$\mathrm{G}(4.3612,-0.7411,1.6421)$ & $\mathrm{H}(4.3612,-1.0311,1.6403)$ & $\mathrm{I}(4.3612,-0.7411,1.7221)$ & $\mathrm{J}(4.3612,-1.0321,1.7221)$ \\
$\mathrm{G}_{1}(4.3612,-0.7411,1.2421)$ & $\mathrm{H}_{1}(4.3612,-1.0311,1.24)$ & $\mathrm{I}_{1}(4.3612,-0.7411,1.5721)$ & $\mathrm{J}_{1}(4.3612,-1.0321,1.5721)$ \\
$\mathrm{K}_{1}(1.4412,-0.7811,1.8902)$ & $\mathrm{L}_{1}(1.4412,-1.0711,1.8902)$ & $\mathrm{M}_{1}(0.8121,-1.0711,1.8902)$ & $\mathrm{N}_{1}(0.8121,-0.7811,1.8902)$ \\
$\mathrm{K}(3.3812,-0.7811,1.8902)$ & $\mathrm{L}(3.3812,-1.0711,1.8902)$ & $\mathrm{M}(2.7512,-1.0711,1.8902)$ & $\mathrm{N}(2.7522,-0.7811,1.8902)$ \\
\hline
\end{tabular}

2. The corresponding letters of the display and control console in the cabin are shown in Figure 3, and the corresponding coordinates of each letter are shown in Table 3.

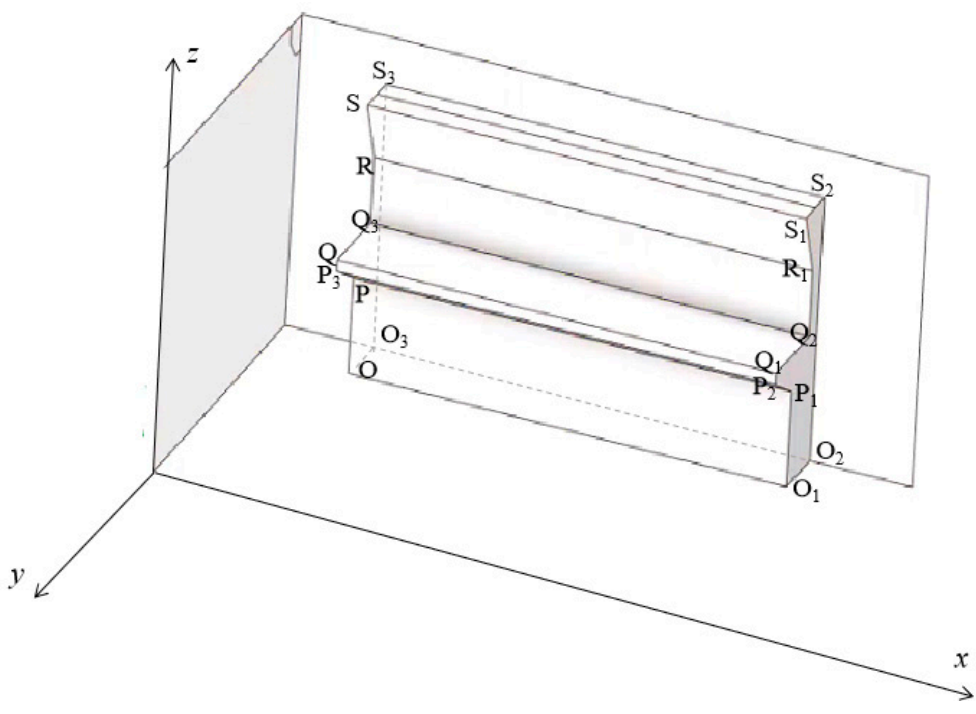

Figure 3. The corresponding letters of the display and control console. 
Table 3. The corresponding coordinates of each letter in the display and control console.

\begin{tabular}{llll}
\hline & \multicolumn{3}{c}{ The Position of Letters $(\mathbf{x}, \mathbf{y}, \mathbf{z})$} \\
\hline $\mathrm{O}(0.6413,-1.7432,0.0000)$ & $\mathrm{O}_{1}(3.6421,-1.7432,0.0000)$ & $\mathrm{O}_{2}(3.6421,-2.3722,0.0000)$ & $\mathrm{O}_{3}(0.6412,-2.3722,0.0000)$ \\
$\mathrm{P}(0.6413,-1.7432,0.6713)$ & $\mathrm{P}_{1}(3.6421,-1.7432,0.6713)$ & $\mathrm{P}_{2}(3.6421,-1.4351,0.7620)$ & $\mathrm{P}_{3}(0.6412,-1.43531,0.7620)$ \\
$\mathrm{Q}(0.6413,-1.4353,0.8213)$ & $\mathrm{Q}_{1}(3.6421,-1.4351,0.8213)$ & $\mathrm{Q}_{2}(3.6421,-1.9121,0.8112)$ & $\mathrm{Q}_{3}(0.6412,-1.9121,0.8246)$ \\
$\mathrm{R}(0.6413,-1.9121,1.2133)$ & $\mathrm{R}_{1}(3.6421,-1.9121,1.2133)$ & & \\
$\mathrm{S}(0.6413,-2.0403,1.6213)$ & $\mathrm{S}_{1}(3.6421,-2.0403,1.6213)$ & $\mathrm{S}_{2}(3.6421,-2.3732,1.6221)$ & $\mathrm{S}_{3}(0.6412,-2.3722,1.6221)$ \\
\hline
\end{tabular}

3. The letters corresponding to the air supply outlets are shown in Figure 4, and the corresponding coordinates of each letter are shown in Table 4.

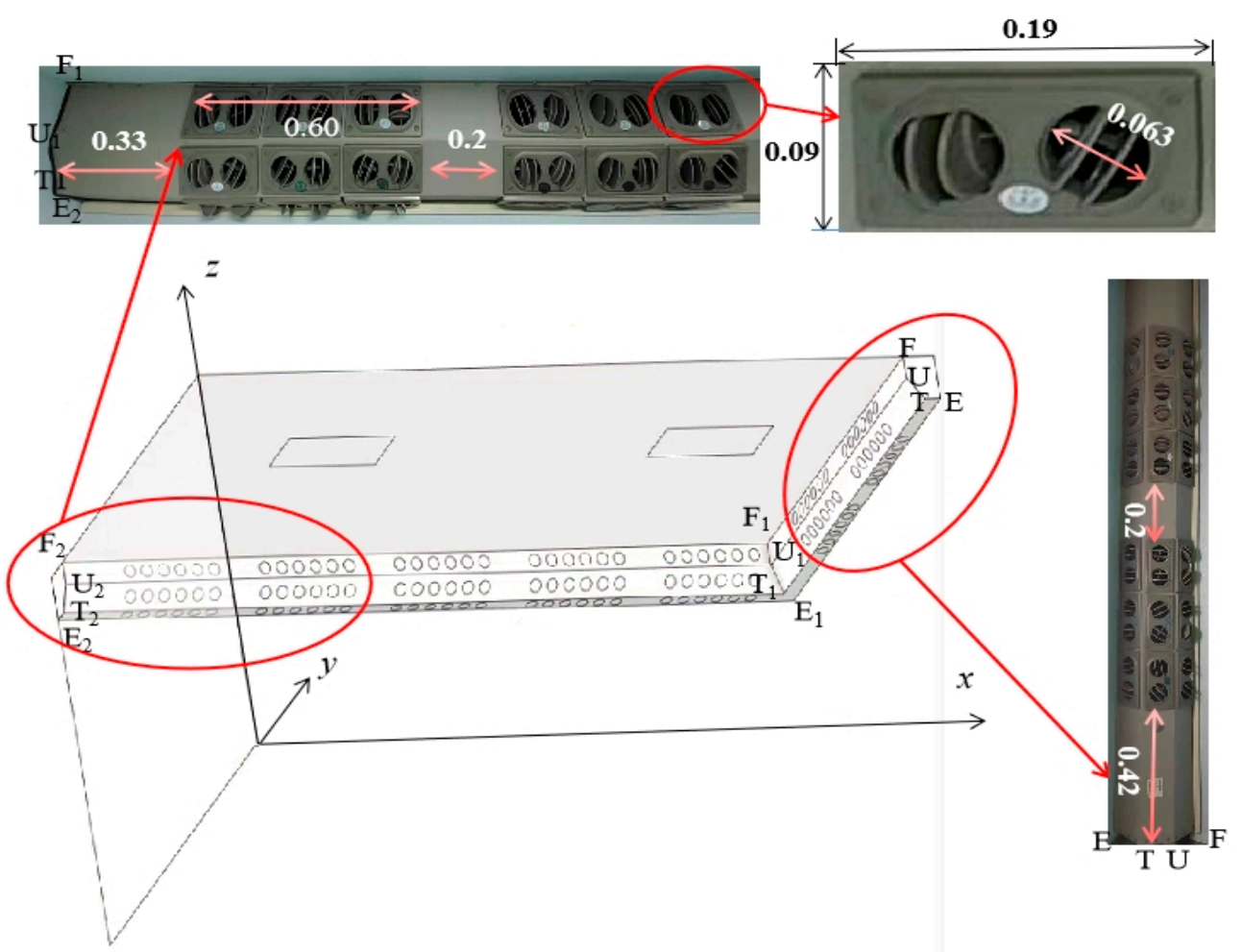

Figure 4. The letters corresponding to the air supply outlets.

Table 4. The corresponding coordinates of each letter in the air supply outlets.

\begin{tabular}{lll}
\hline & The Position of Letters $(\mathbf{x}, \mathbf{y}, \mathbf{z})$ & \\
\hline $\mathrm{E}(4.3602,0.0000,1.5922)$ & $\mathrm{E}_{1}(4.3602,-2.3723,1.5922)$ & $\mathrm{E}_{2}(0.0000,-2.3723,1.5922)$ \\
\hline $\mathrm{F}(4.1603,0.0000,1.8912)$ & $\mathrm{F}_{1}(4.1603,-2.1716,1.8912)$ & $\mathrm{F}_{2}(0.0000,-2.1716,1.8912)$ \\
\hline $\mathrm{U}(4.1603,0.0000,1.7821)$ & $\mathrm{U}_{1}(4.1603,-2.1716,1.7821)$ & $\mathrm{U}_{2}(0.0000,-2.1716,1.7821)$ \\
\hline $\mathrm{T}(4.2621,0.0000,1.5923)$ & $\mathrm{T}_{1}(4.2621,-2.2702,1.5923)$ & $\mathrm{T}_{2}(0.0000,-2.2702,1.5923)$ \\
\hline
\end{tabular}

\subsubsection{Composition of Subjects}

Ten groups of subjects were composed of three junior and senior cadets from university. The height, weight, age, and training durations of the subjects were recorded. The heights of the subjects ranged from 1.68 to $1.88 \mathrm{~m}$, weight from 60 to $89.5 \mathrm{~kg}$, and exercise duration from 0.5 to $2 \mathrm{~h}$ per day. The experiment was conducted with short and long clothes respectively, and the basic information of the subjects is shown in Table 5. The surface area of each person was calculated using the method in [31]. 
Table 5. Basic information of the subjects.

\begin{tabular}{|c|c|c|c|c|c|c|c|}
\hline \multicolumn{2}{|c|}{ Group } & $\begin{array}{l}\text { Height } \\
\text { (cm) }\end{array}$ & $\begin{array}{l}\text { Weight } \\
\text { (kg) }\end{array}$ & Age & $\begin{array}{l}\text { Exercise Time } \\
\text { (hour) }\end{array}$ & $\begin{array}{c}\text { Surface Area } \\
\left(\mathrm{m}^{2}\right)\end{array}$ & Dress \\
\hline \multirow{3}{*}{1} & A & 1.742 & 70.2 & 22 & 1 & 1.8754 & \multirow{3}{*}{ Short sleeves and shorts } \\
\hline & $\mathrm{B}$ & 1.823 & 73.3 & 22 & 1 & 1.9621 & \\
\hline & C & 1.701 & 71.4 & 21 & 1 & 1.8638 & \\
\hline \multirow{3}{*}{2} & A & 1.698 & 73.2 & 26 & 1.5 & 1.8831 & \multirow{3}{*}{ Long sleeves and pants } \\
\hline & B & 1.742 & 70.6 & 23 & 1.5 & 1.8754 & \\
\hline & $\mathrm{C}$ & 1.702 & 67.1 & 26 & 1.5 & 1.8130 & \\
\hline \multirow{3}{*}{3} & $\mathrm{~A}$ & 1.751 & 65.5 & 25 & 1 & 1.8179 & \multirow{3}{*}{ Short sleeves and shorts } \\
\hline & B & 1.723 & 68.3 & 25 & 1 & 1.8378 & \\
\hline & $\mathrm{C}$ & 1.701 & 62.2 & 21 & 1 & 1.7495 & \\
\hline \multirow{3}{*}{4} & A & 1.703 & 64.7 & 22 & 1 & 1.7749 & \multirow{3}{*}{ Long sleeves and pants } \\
\hline & B & 1.842 & 75.3 & 20 & 1.5 & 1.9996 & \\
\hline & C & 1.811 & 76.1 & 21 & 1 & 1.9941 & \\
\hline \multirow{3}{*}{5} & A & 1.823 & 79.8 & 20 & 1.5 & 2.0382 & \multirow{3}{*}{$\begin{array}{l}\text { Shorty/Long } \\
\text { sleeves and pants }\end{array}$} \\
\hline & B & 1.751 & 66.2 & 20 & 1.5 & 1.8307 & \\
\hline & C & 1.832 & 77.1 & 20 & 1.5 & 2.0189 & \\
\hline \multirow{3}{*}{6} & $\mathrm{~A}$ & 1.703 & 76.3 & 25 & 1.5 & 1.9273 & \multirow{3}{*}{ Long sleeves and pants } \\
\hline & B & 1.782 & 76.2 & 20 & 2 & 1.9759 & \\
\hline & C & 1.721 & 68.1 & 21 & 2 & 1.8378 & \\
\hline \multirow{3}{*}{7} & A & 1.833 & 72.3 & 21 & 1.5 & 1.9554 & \multirow{3}{*}{ Short sleeves and shorts } \\
\hline & B & 1.752 & 71.1 & 21 & 1.5 & 1.8942 & \\
\hline & $\mathrm{C}$ & 1.784 & 70.2 & 22 & 1.5 & 1.8997 & \\
\hline \multirow{3}{*}{8} & A & 1.742 & 60.1 & 22 & 1 & 1.7484 & \multirow{3}{*}{$\begin{array}{c}\text { Shorty/Long } \\
\text { sleeves and pants }\end{array}$} \\
\hline & $\mathrm{B}$ & 1.843 & 83.4 & 25 & 1 & 2.1012 & \\
\hline & C & 1.824 & 75.2 & 22 & 1 & 1.9874 & \\
\hline \multirow{3}{*}{9} & $\mathrm{~A}$ & 1.712 & 61.1 & 21 & 1 & 1.7429 & \multirow{3}{*}{ Long sleeves and pants } \\
\hline & $\mathrm{B}$ & 1.883 & 89.5 & 23 & 1 & 2.2017 & \\
\hline & C & 1.752 & 70.3 & 24 & 1 & 1.8815 & \\
\hline \multirow{3}{*}{10} & $\mathrm{~A}$ & 1.724 & 65.1 & 23 & 0.5 & 1.7998 & \multirow{3}{*}{ Short sleeves and shorts } \\
\hline & B & 1.683 & 65.2 & 23 & 0.5 & 1.7755 & \\
\hline & $\mathrm{C}$ & 1.811 & 77.3 & 23 & 1 & 2.0068 & \\
\hline
\end{tabular}

\subsubsection{Experimental Conditions}

The experiment was divided into two parts: In the first part, with no subject and the control board closed, the thermal environment experiments with 9 working conditions were completed. In the second part, on the basis of the first part, the typical working conditions were determined, the control console was opened, and the human body temperature distribution experiments were completed. The nine conditions involved refrigeration $\left(28-16{ }^{\circ} \mathrm{C}, 28-1{ }^{\circ} \mathrm{C}, 28-20^{\circ} \mathrm{C}\right)$, ventilation $\left(24{ }^{\circ} \mathrm{C}, 26^{\circ} \mathrm{C}, 28{ }^{\circ} \mathrm{C}\right)$, or heating $\left(24-31^{\circ} \mathrm{C}\right.$, $\left.26-31{ }^{\circ} \mathrm{C}, 28-31^{\circ} \mathrm{C}\right)$. The distribution of specific working conditions is shown in Table 6. The front temperature was the initial indoor temperature, and the rear temperature was the expected temperature, to be met through the regulation of the air supply system.

Table 6. Experimental conditions of the thermal environment in the unmanned shelter.

\begin{tabular}{ccc}
\hline Refrigeration Condition & Ventilation Condition & Heating Conditions \\
\hline Case $1: 28-16^{\circ} \mathrm{C}$ & Case $4: 24-30{ }^{\circ} \mathrm{C}$ & Case $7: 24-31^{\circ} \mathrm{C}$ \\
Case $2: 28-18{ }^{\circ} \mathrm{C}$ & Case $5: 26-30{ }^{\circ} \mathrm{C}$ & Case $8: 26-31^{\circ} \mathrm{C}$ \\
Case $3: 28-20{ }^{\circ} \mathrm{C}$ & Case 6: $28-30{ }^{\circ} \mathrm{C}$ & Case $9: 28-31^{\circ} \mathrm{C}$ \\
\hline
\end{tabular}




\subsection{Location Selection for Sensors in the Shelter}

2.2.1. Selection of Measuring Points for the Experiments

1 Selection of measuring points for the experiments in the unmanned shelter

The shelter was composed of two fluid areas: one was the airflow distribution in the pipe; the other was the airflow distribution in the shelter. In this paper, common measuring points in manned and unmanned cabins were selected for comparative experiments. Seven wind speed measuring points were set up in the pipes, as shown in Figure 5a. Three inlet temperature measuring points were in the air inlets, and five temperature measuring points were in the corresponding outlet. The air outlet and inlet measuring points are shown in Figure 5b. Boundary measurement points of the wall surfaces are shown in Figure 5c.

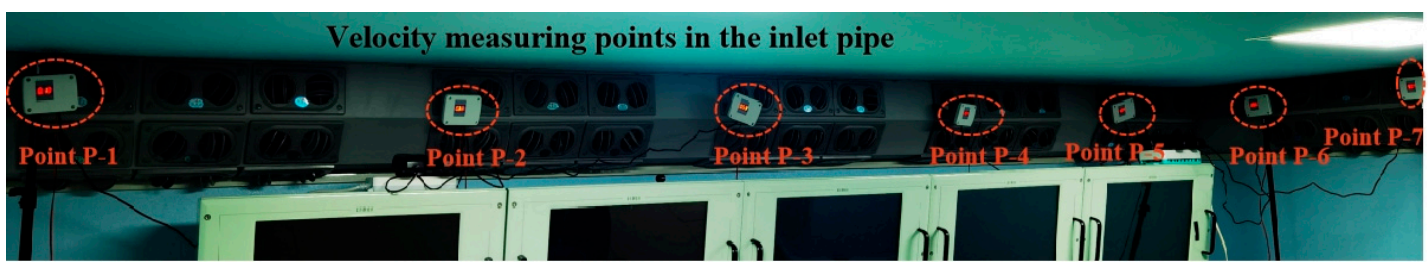

(a)

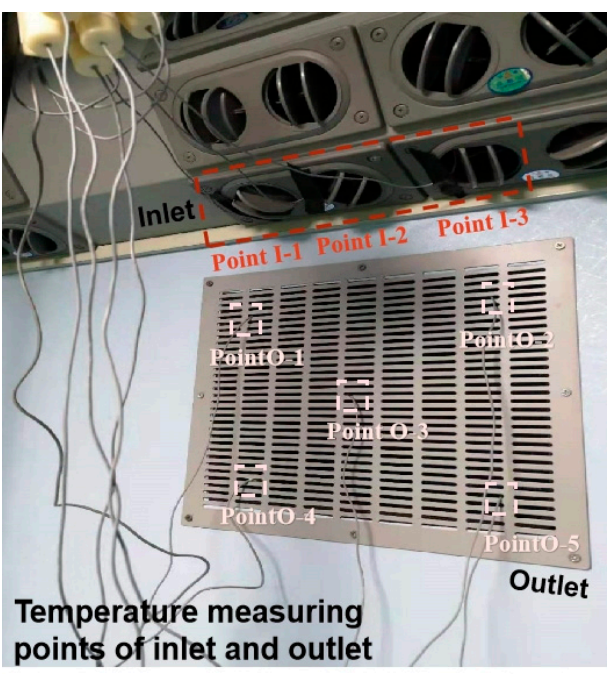

(b)

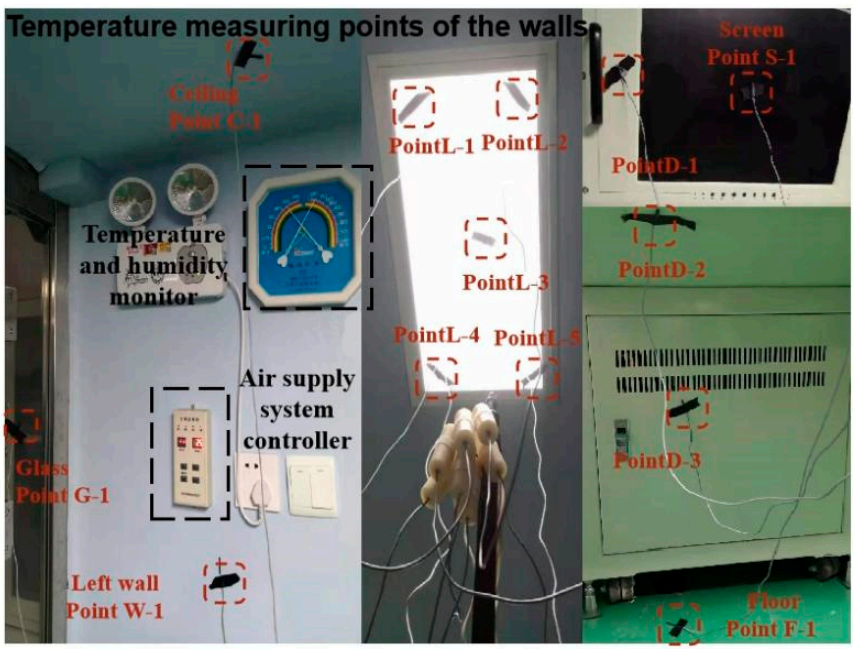

(c)

Figure 5. The positions of measuring points in the unmanned shelter. (a) The positions of measuring points of the air supply pipe. (b) The points at the inlets and outlet. (c) The points on the walls.

The space temperature measuring points R $1-3$ were located in the middle (vertically) on the left side of the chair, on the face a person would make contact with. It is difficult to mark the specific point in the figure, but specific coordinates can be given. The coordinates of the measurement points in the unmanned shelter are shown in Table 7.

Table 7. The coordinates of the measurement points in the unmanned shelter.

\begin{tabular}{ll}
\hline & \multicolumn{1}{c}{ Coordinates of Different Measuring Points in Each Equipment $(\mathbf{x}, \mathbf{y}, \mathbf{z})$} \\
\hline Point $\mathrm{P}$ & $1(0.37,-2.17,1.83), 2(1.17,-2.17,1.83), 3(1.97,-2.17,1.83), 4(2.77,-2.17,1.83), 5(3.57,-2.17,1.83)$ \\
Point I & $6(4.16,-1.77,1.83), 7(0.97,-0.97,1.83)$ \\
Point $\mathrm{O}$ & $1(4.31,-0.99,1.59), 2(4.31,-0.89,1.59), 3(4.31,-0.79,1.59)$ \\
Point C & $1(4.36,-1.05,1.50), 2(4.36,-0.82,1.50), 3(4.36,-0.92,1.38), 4(4.36,-1.05,1.26), 5(4.36,-0.82,1.26)$ \\
\hline
\end{tabular}


Table 7. Cont.

\begin{tabular}{ll}
\hline & Coordinates of Different Measuring Points in Each Equipment $(\mathbf{x}, \mathbf{y}, \mathbf{z})$ \\
\hline Point $\mathrm{G}$ & $1(0.68,0,1.44), 2(0.68,0,0.45), 3(2.29,0,0.95), 4(3.91,-0,1.44), 5(3.91,0,0.45)$ \\
& $1(0,-0.45,1.44), 2(0,-1.92,1.44), 3(0,-1.18,0.95), 4(0,-0.45,0.45), 5(0,-1.92,0.45)$ \\
Point $\mathrm{W}$ & $6(0.68,-2.37,1.44), 7(0.68,-2.37,0.45), 8(2.29,-2.37,0.95), 9(3.91,-2.37,1.44), 10(3.91,-2.37,0.45)$ \\
& $11(4.36,-0.45,1.44), 12(4.36,-1.92,1.44), 13(4.36,-1.18,0.95), 14(4.36,-0.45,0.45), 15(4.36,-1.92,0.45)$ \\
Point L & $1(0.9,-0.88,1.89), 2(0.9,-1.08,1.89), 3(1.13,-0.98,1.89), 4(1.36,-0.88,1.89), 5(1.36,-1.08,0.1 .89)$ \\
& $6(3.46,-0.88,1.89), 7(3.46,-1.08,1.89), 8(3.23,-0.98,1.89), 9(3,-0.88,1.89), 10(3,-1.08,0.1 .89)$ \\
Point S & $1(0.95,-2.06,1.36), 2(1.55,-2.06,1.36), 3(2.15,-2.06,1.36), 4(2.75,-2.06,1.36), 5(3.35,-2.06,1.36)$ \\
& $6(0.95,-2.11,1.01), 7(1.55,-2.11,1.01), 8((2.15,-2.11,1.01), 9(2.75,-2.11,1.01), 10(3.35,-2.11,1.01)$ \\
Point D & $1(0.69,-2.06,1.36), 2(1.29,-2.06,1.36), 3(1.89,-2.06,1.36), 4(2.49,-2.06,1.36), 5(3.09,-2.06,1.36)$ \\
& $6(0.69,-2.11,1.01), 7(1.29,-2.11,1.01), 8(1.89,-2.11,1.01), 9(2.49,-2.11,1.01), 10(3.09,-2.11,1.01)$ \\
Point F & $1(0.95,-1.59,0.67), 2(1.55,-1.59,0.67), 3(2.15,-1.59,0.67), 4(2.75,-1.59,0.67), 5(3.35,-1.59,0.67)$ \\
Point R & $6(0.95,-1.74,0.34), 7(1.55,-1.74,0.34), 8((2.15,-1.74,0.34), 9(2.75,-1.74,0.34), 10(3.35,-1.74,0.34)$ \\
\hline
\end{tabular}

2. Selection of measuring points for the manned shelter thermal environment experiment

When conducting thermal environment experiments in the manned shelter, five display control consoles were opened, with a total of ten display interfaces. The temperatures of the consoles were measured, and the measuring points were the same as in Figure $5 \mathrm{~b}, \mathrm{c}$. The 14-point method [31] was adopted to measure the temperatures of the three subjects' bodies in each group wearing short or long clothing. The specific measurement process is shown in Figure 6. The 14 measurement points were head, chest, left and right upper arms, left and right lower arms, left and right hands, left and right thighs, left and right calves, and left and right ankles. The distribution of measurement points is shown in Figure 7.

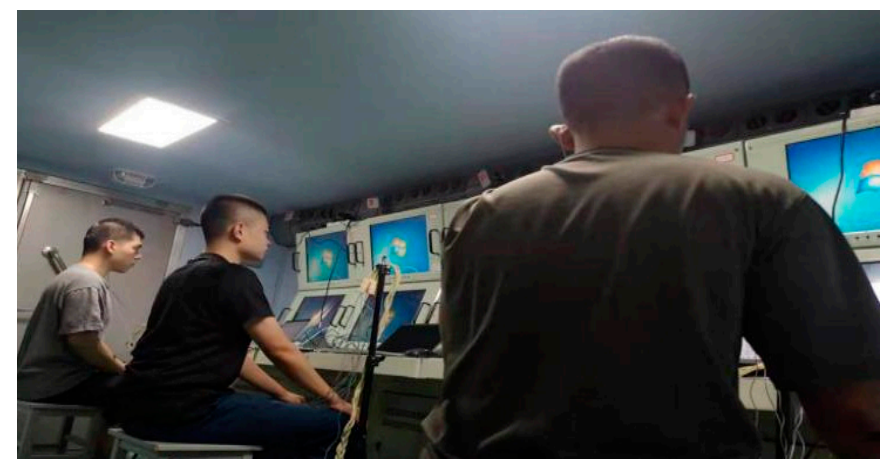

(a)

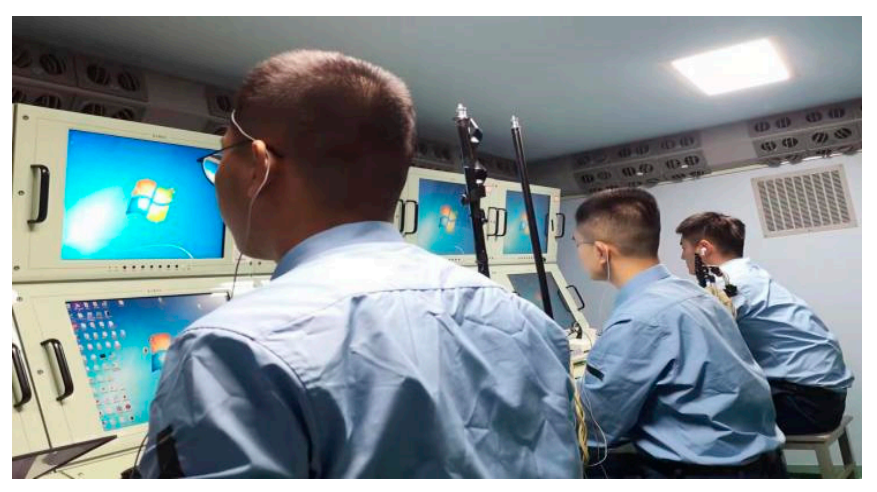

(b)

Figure 6. The subjects wearing long and short clothing in the manned shelter. (a) Short clothing experiment. (b) Long clothing experiment. 


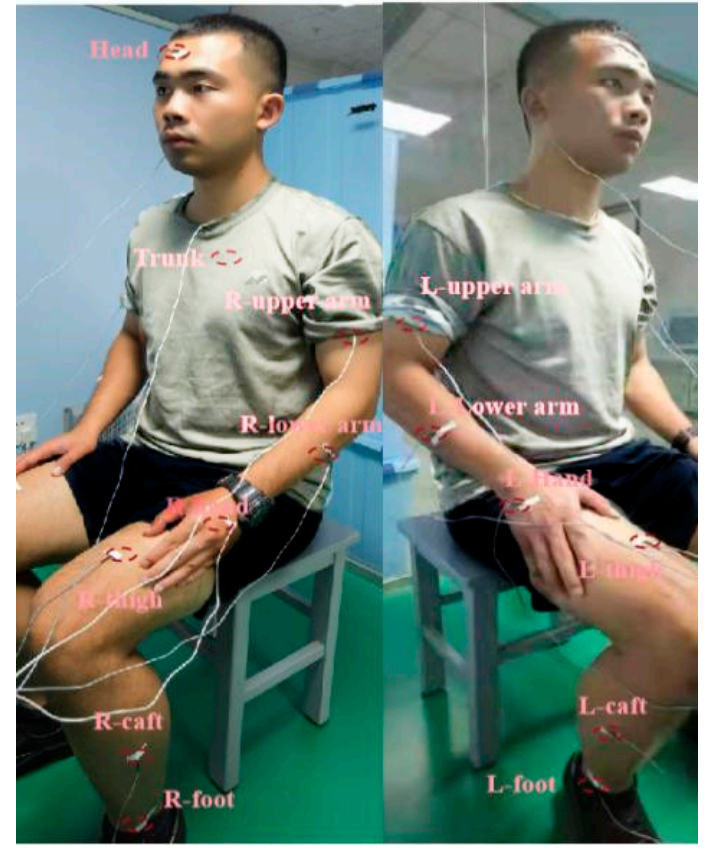

Figure 7. Distribution of human body temperature measurement points.

\subsubsection{Selection of Measuring Surfaces for Thermal Environment Experiments}

In both manned and unmanned experiments, the experimental surfaces for wind speed were the same. The surface used for wind speed was parallel to the display control console and intersected with the humans; see Surface 4 in Figure 8. The profile of wind speed was perpendicular to the display control console, and the three humans were each divided in two along the sagittal plane; see Surfaces 1-3. Specific experimental surfaces are shown in Figure 8.

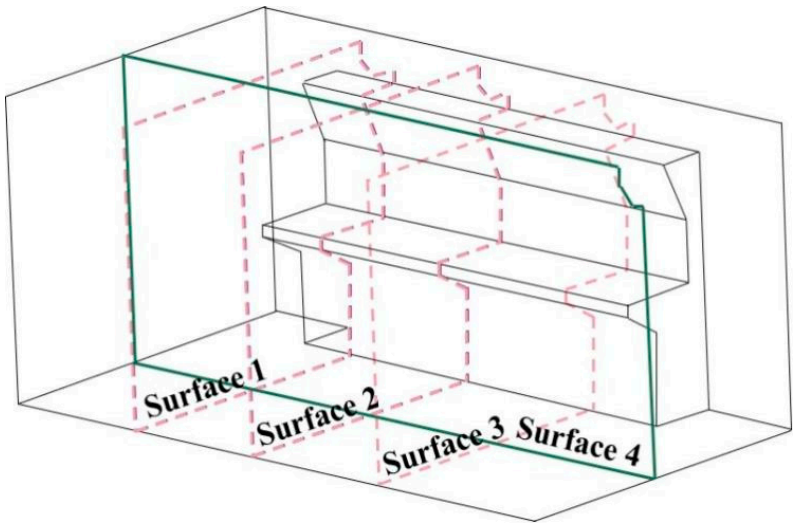

(a)

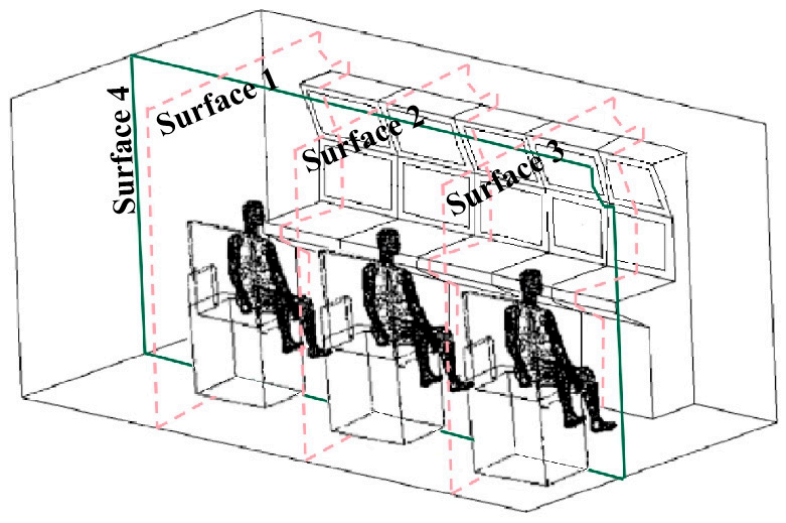

(b)

Figure 8. Measuring surfaces for manned and unmanned cabin tests. (a) The measuring surfaces for unmanned. (b)The measuring surfaces for manned.

\subsubsection{The Uncertainties of the Length, Height, and Weight Measurements}

1. The assessment of measurement uncertainties in length measurements

When measuring the length $d$ of a device, each length or coordinate is measured $n$ times. The whole process includes: (1) the position error of the equipment during measurement; (2) the uncertainty component of one end of the equipment against zero; (3) the uncertainty of the reading at the other end, including the component caused by 
parallax and the uncertainty caused by distance. The experimental standard deviation $s\left(d_{i}\right)$ was calculated from the independent measurement results. In fact, in addition to the repeatability standard deviation $s_{r}$ of the measuring instrument itself, the uncertainty components from the above three factors were also included. Therefore, in this case, it was not necessary to evaluate these components separately and synthesize them, but the synthetic standard deviation could be obtained from the $n$ measurement results once. When evaluating the uncertainty of the measurement of length $d$, the mean value of $n$ times is calculated first and summed with the correction parameter $C$ of the equipment.

$$
\bar{d}=\frac{1}{n} \sum_{i=1}^{n} d_{i}, d=\bar{d}+C
$$

The actual standard deviation is

$$
s\left(d_{i}\right)=\sqrt{\frac{1}{n-1} \sum_{i=1}^{n}\left(d_{i}-\bar{d}\right)^{2}}
$$

$s(\bar{d})$ is the arithmetic average, and $u(\bar{d})$ is the arithmetic average of $\bar{d}$.

$$
u(\bar{d})=s(\bar{d})=\frac{s\left(d_{i}\right)}{\sqrt{n}}
$$

The degrees of freedom of $s(\bar{d})$ are the same as those of $s\left(d_{i}\right)$; both are $v=n-1$. The probability distribution $\bar{d}$ that can be estimated according to the central limit theorem is close to normal. If the heart of hope probability is $95 \%$ and the extended uncertainty $U_{95}$ is given, one can look up the table and get $t_{95}(n)$.

$$
U_{95}=t_{95}(n) \times u(\bar{d})
$$

According to the normal modification rule, the effective number of $U_{95}$ should not exceed two digits, and the modification number can be obtained. Finally, we can figure out the number of significant digits we should keep.

$$
d=\bar{d}+C+U_{95}
$$

2. The assessment of measurement uncertainties in human surface area

The height and weight of each human were measured $n$ times in each group, so there were uncertainties from both measurements to deal with.

One can calculate the average values $\bar{h}$ and $\bar{m}$ of $n$ measurements, and then calculate the human surface area using the surface area formula:

$$
A=0.00607 h+0.0127 m-0.0698
$$

The standard uncertainties were calculated as

$$
\begin{gathered}
u_{A}(\bar{h})=s_{A}(\bar{h})=\frac{s\left(h_{i}\right)}{\sqrt{n}} \\
u_{A}(\bar{m})=s_{A}(\bar{m})=\frac{s\left(m_{i}\right)}{\sqrt{n}}
\end{gathered}
$$

The degrees of freedom are $v=n-1$. The $h$ and $m$ allow error ranges of $\pm 0.1 \mathrm{~mm}$ and $0.001{ }^{\circ} \mathrm{C}$. The error ranges can be considered those of half broadband.

$$
u_{B}(\bar{h})=\mathrm{a}_{h} / \sqrt{3}
$$




$$
u_{B}(\bar{m})=\mathrm{a}_{m} / \sqrt{3}
$$

Thus, the mixed uncertainty of the two can be obtained:

$$
\begin{aligned}
u_{C}(\bar{h}) & =\sqrt{u_{A}(\bar{h})+u_{B}(\bar{h})} \\
u_{C}(\bar{m}) & =\sqrt{u_{A}(\bar{m})+u_{B}(\bar{m})}
\end{aligned}
$$

The degrees of freedom calculations are as follows.

$$
\begin{aligned}
& v_{e f f}(d)=\frac{u_{C}^{4}(\bar{h})}{\frac{u_{A}^{4}(\bar{h})}{5}+\frac{u_{B}^{4}(\bar{h})}{\infty}} \\
& v_{e f f}(m)=\frac{u_{C}^{4}(\bar{m})}{\frac{u_{A}^{4}(\bar{m})}{5}+\frac{u_{B}^{4}(\bar{m})}{\infty}}
\end{aligned}
$$

Finally, there are

$$
\begin{gathered}
{\left[\frac{u_{\mathcal{c}}(A)}{A}\right]^{2}=\left[2 u_{c}(\bar{h}) / \bar{h}\right]^{2}+\left[u_{c}(\bar{m}) / \bar{m}\right]^{2}} \\
u_{c}(\bar{A})=\frac{u_{c}(A)}{A}
\end{gathered}
$$

Since the effective degrees of freedom are all large, it is unnecessary to calculate the effective degrees of freedom of $u_{c}(A)$. The probability distribution of $u_{c}(A)$ can be estimated as normal distribution, so the confidence probability is $95 \%$, and the extended uncertainty of $A$ is

$$
U_{95}=2 u_{c}(\bar{A})
$$

Finally, it can be expressed as

$$
A=\left(A+U_{95}\right)
$$

Based on the measurement uncertainty evaluation method in this section, the coordinates were accurate to $0.01 \mathrm{~m}$, and the temperature measurements were accurate to $0.01^{\circ} \mathrm{C}$. The coordinates and temperature were measured 20 times each. According to the calculations, the U95 of the coordinates, temperature, and area were $0.0011 \mathrm{~m}, 0.013{ }^{\circ} \mathrm{C}$, and $0.0057 \mathrm{~m}$.

\section{Data and Processing Analysis}

\subsection{Temperature Measurement Points Analysis}

3.1.1. Data Analysis of Temperature Measuring Points in the Shelter

The temperature distribution of the points at the boundary conditions in the shelter was first measured in the unattended experiment when the air conditioning unit was not turned on. Measuring points mainly included the walls, ceiling, ground, control table, lamps, etc. (see Table 8). The initial values of boundary measurement points at $24{ }^{\circ} \mathrm{C}, 26^{\circ} \mathrm{C}$, and $28^{\circ} \mathrm{C}$ are shown in the table.

After the boundary conditions were measured, the same monitoring points on Surfaces 1-3 were monitored under the conditions of refrigeration (cases 1-3), heating (cases 4-6), and ventilation (cases 7-9). The temperature of each monitoring surface was averaged, so as to obtain the temperature change rule of the monitoring points on each monitoring surface. 
Table 8. Temperatures of select measuring points for experimental boundary conditions.

\begin{tabular}{cccc}
\hline The Temperature of the Room $\left({ }^{\circ} \mathrm{C}\right)$ & Temperature 24 & Temperature 26 & Temperature 28 \\
\hline Left wall measurement temperature $\left({ }^{\circ} \mathrm{C}\right)$ & 26.710 & 27.061 & 28.712 \\
\hline Right wall measurement temperature $\left({ }^{\circ} \mathrm{C}\right)$ & 26.801 & 27.473 & 29.459 \\
\hline Back wall measurement temperature $\left({ }^{\circ} \mathrm{C}\right)$ & 26.811 & 26.811 & 29.616 \\
\hline Glass wall measurement temperature $\left({ }^{\circ} \mathrm{C}\right)$ & 26.802 & 26.291 & 28.886 \\
\hline Floor wall measurement temperature $\left({ }^{\circ} \mathrm{C}\right)$ & 25.502 & 27.402 & 28.916 \\
\hline Light measurement temperature $\left({ }^{\circ} \mathrm{C}\right)$ & 33.554 & 33.884 & 33.779 \\
\hline Ceiling measurement temperature $\left({ }^{\circ} \mathrm{C}\right)$ & 27.571 & 27.001 & 29.773 \\
\hline & 28.863 & 29.342 & 32.117 \\
Display control station temperature $\left({ }^{\circ} \mathrm{C}\right)$ & 27.822 & 28.552 & 31.529 \\
\hline $\begin{array}{c}\text { Chair measurement temperature }\left({ }^{\circ} \mathrm{C}\right) \\
\text { (Human body) }\end{array}$ & 26.142 & 27.634 & 29.397 \\
\hline Display interface temperature & 31.201 & 31.804 & 32.002 \\
\hline (Human body) & 33.093 & 33.233 & 33.423 \\
\hline
\end{tabular}

We opened the air supply system, selected the refrigeration mode, and monitored the corresponding measuring points to obtain the average temperature changes with time. For refrigerated conditions (cases 1-3), the mean temperature distributions of measuring points over time are shown in Figure 9. It shows the variations in temperature with time under the three set temperatures. After the starting temperature of $28^{\circ} \mathrm{C}$, the temperature trends were constant, other than that when the set temperature was reached, the temperature no longer dropped, but began to fluctuate within a range of about $2{ }^{\circ} \mathrm{C}$.

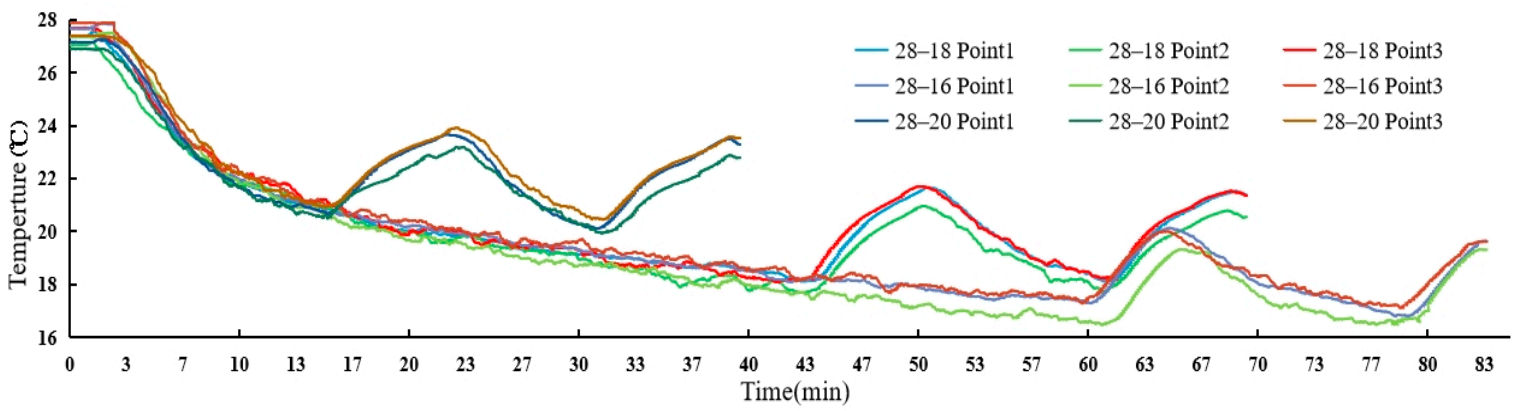

(a)

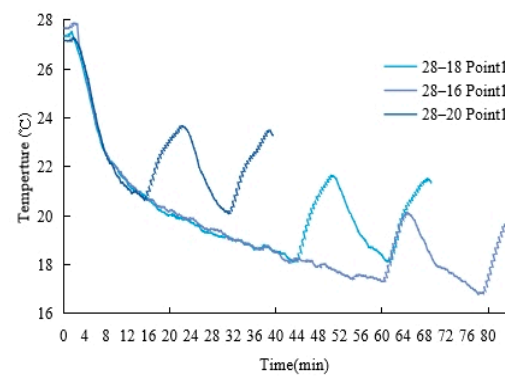

(b)

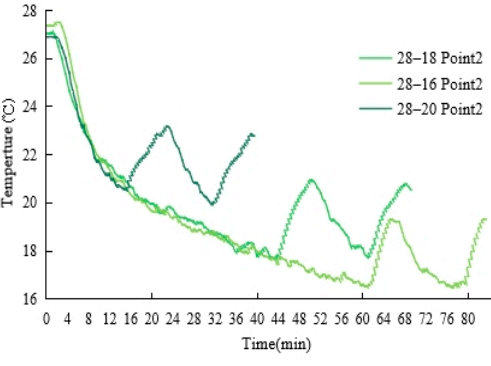

(c)

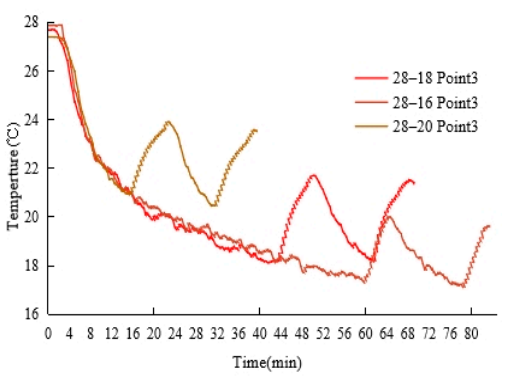

(d)

Figure 9. Temperature time series distribution of monitoring points under refrigeration. (a) Temperature distribution of three points in cases 1-3. (b) Temperature distribution of the point1 in cases 1-3. (c) Temperature distribution of the point 2 in cases 1-3. (d) Temperature distribution of the point 3 in cases 1-3.

According to the analysis of Figure 9a, in the refrigerated conditions, the temperature of measuring point 2 in cases 1-3 was generally lower than at points 1 and 3 . The temperature trends of each measuring point were the same. The same air supply temperature was 
used for air supply in cases 1-3. Under refrigeration, it can be seen in Figure $9 b-d$ that the temperature dropped rapidly at the beginning and slowly thereafter. It took about $13 \mathrm{~min}$ for the temperature to drop from 28 to $20^{\circ} \mathrm{C}$, about 43 min to drop from 28 to $18{ }^{\circ} \mathrm{C}$, and more than an hour to drop from 28 to $16^{\circ} \mathrm{C}$. The graph shows that the temperature eventually approached constant value in each case. The experimental curves of the measurement points in different cases can be expressed by functions. The time required for each point to reach the set temperature can be calculated, and the fluctuation range can be obtained by Equation (19).

$$
y_{c}=\left\{\begin{array}{c}
a_{1}-b_{1} \ln \left(x+c_{1}\right), \quad y_{c} \leq \text { setpo int } \\
A_{1}+\sum_{i=1}^{9} B_{i} \times x^{i}, \quad y_{c} \geq \text { setpo int } i=1,2,3 \ldots 9
\end{array}\right.
$$

In the equation, $x$ is time in minutes; $y_{c}$ is temperature in ${ }^{\circ} \mathrm{C} ; a_{1}, b_{1}$, and $c_{1}$ are constants in the logarithmic function; $A_{1}$ and $b_{i}$ are constants in the polynomial; and $I$ is the number of terms. In case $1 i=9$, in case $2 i=7$, and in case $3 i=5$.

For the ventilation experiments (cases 4-6), the distributions of average temperature at measurement points over time are shown in Figure 10. It shows the change sequences of temperature with time under three scenarios. The temperature inside the shelter was 26-27 ${ }^{\circ} \mathrm{C}, 27-28^{\circ} \mathrm{C}$, or $28-29^{\circ} \mathrm{C}$, respectively. The temperature rose rapidly in the first $6 \mathrm{~min}$ (but slowly in the latter case), and finally approached the outside temperature of the shelter of about $29-30{ }^{\circ} \mathrm{C}$ (error of $0.5^{\circ} \mathrm{C}$ ).

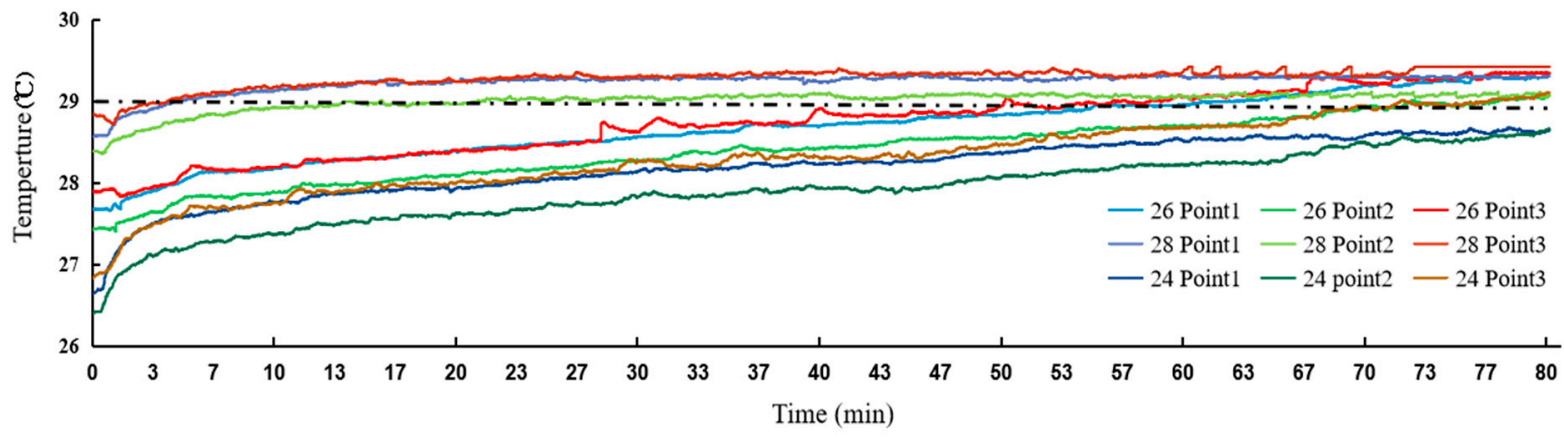

(a)

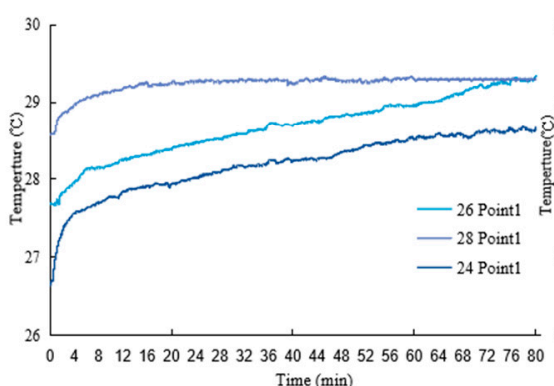

(b)

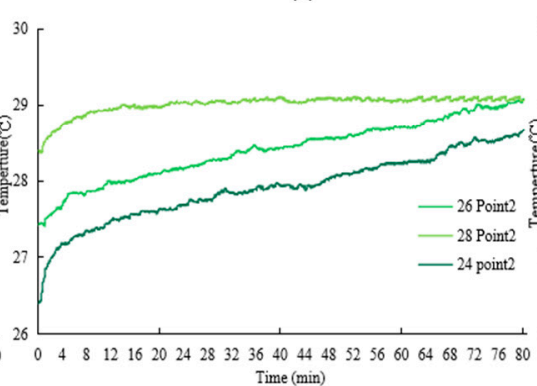

(c)

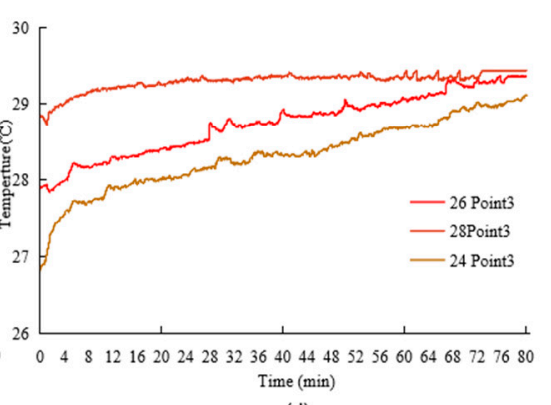

(d)

Figure 10. Temperature time series distributions at monitoring points with ventilation provided. (a) Temperature distribution of three points in cases 4-6. (b) Temperature distribution of the point1 in cases 4-6. (c) Temperature distribution of the point 2 in cases 4-6. (d) Temperature distribution of the point 3 in cases $4-6$.

According to the analysis of Figure 10a, with ventilation, the temperature of measuring point 2 in cases 4-6 was generally lower than those of points 1 and 3 . As the temperature was lower, the upward trend was more obvious. It can be seen that the indoor temperature eventually approached the outdoor temperature under ventilation. The temperature rose 
rapidly at the beginning and then slowly; see Figure 10b-d. The experimental curves of different measuring points in different cases can be expressed by the Equation (20).

$$
y_{v}=A_{2}+\sum_{j} B_{j} \times x^{j} \quad j=1,2,3 \ldots 9
$$

In the equation, $x$ is time in minutes, $y_{v}$ is temperature in ${ }^{\circ} \mathrm{C}, A_{2}$ and $B_{j}$ are constants in the polynomial, and $j$ is the number of terms. In cases $4-6, j=9$.

For the heating experiments (cases 7-9), the mean temperature distributions over time of the measurement points are shown in Figure 11. The target temperature was set to $31^{\circ} \mathrm{C}$, and the air supply system was turned on. When the starting temperature was 24 or $26^{\circ} \mathrm{C}$, the temperature rose rapidly and reached a peak (the highest peak), but the temperature did not reach $28{ }^{\circ} \mathrm{C}$, and then it fluctuated while trending upward. After $40 \mathrm{~min}$, the temperature gradually settled into a gentle upward trend. Contrarily, when the starting temperature was $28{ }^{\circ} \mathrm{C}$, there was no peak, just a gentle, continuous rise. In all cases though, it was difficult to reach the set temperature, even after a long time. No matter what the initial temperature was, the temperature did not reach the fixed temperature. After $80 \mathrm{~min}$, the temperature in all cases was between $28.5^{\circ} \mathrm{C}$ and $29.5^{\circ} \mathrm{C}$.

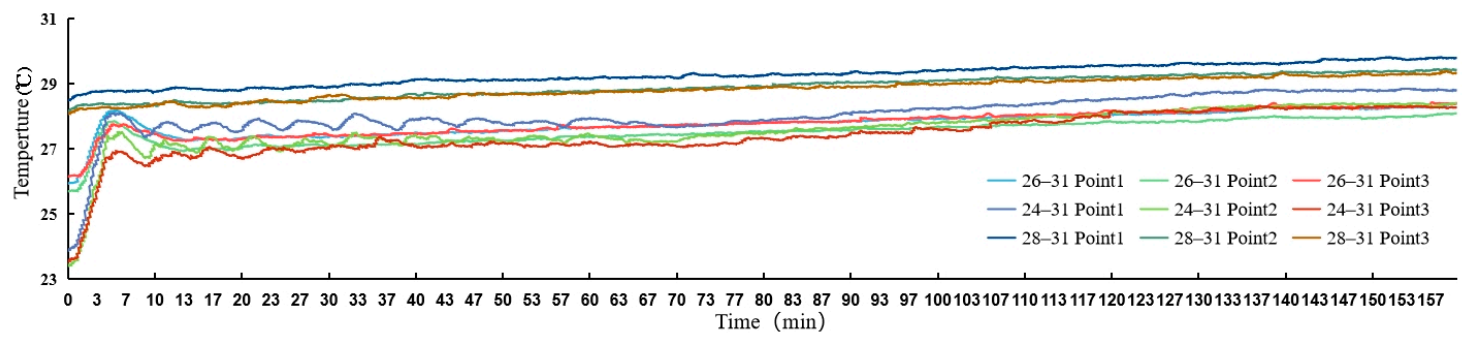

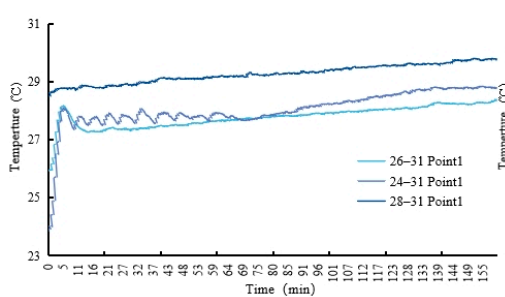

(b)

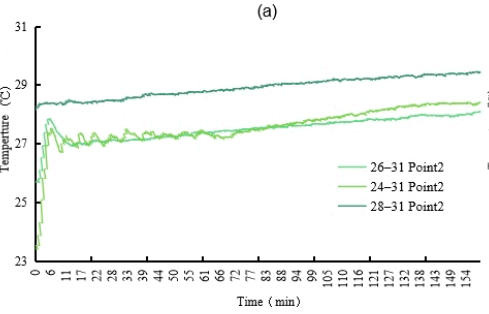

(c)

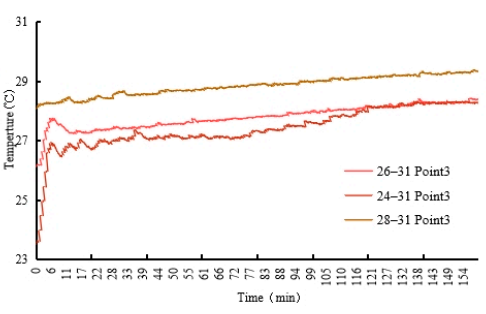

(d)

Figure 11. Temperature time series distributions at monitoring points under ventilated conditions. (a) Temperature distribution of three points in cases 7-9. (b) Temperature distribution of the point1 in cases 7-9. (c) Temperature distribution of the point2 in cases 7-9. (d) Temperature distribution of the point3 in cases 7-9.

According to the experimental data, when the initial temperature was above $28^{\circ} \mathrm{C}$, the temperature basically rose in a straight line. When the temperature was around 26 or $24^{\circ} \mathrm{C}$, the temperature rose rapidly and then began to fluctuate. In the process of fluctuation, the temperature rose gradually. When the initial temperature was high, the fluctuation range was small, and when the temperature was low, the fluctuation range was large. After an hour, the fluctuations stopped, and the temperature began to rise in a straight line. As can be seen in Figure 11 that the shelter temperature did not reach the set temperature.

The fitting curve of case 7 was divided into three parts. The first part is the peak, which could be fitted by a polynomial; the second part is the periodic function of fluctuation, which could be fitted by a sine function; the last part was fitted by cubic function, as shown in Equation (21).

$$
y_{h}=\left\{\begin{array}{c}
A_{3}+\sum_{k} B_{k} \times x^{k} \quad k=1,2,3 \ldots 8 \\
y_{0}+a e^{\left(\frac{-x}{b}\right)} \sin \left(\frac{\pi\left(x-x_{c}\right)}{c}\right) \\
A_{4}+\sum_{m} B_{m} \times x^{m} \quad k=1,2,3
\end{array}\right.
$$


In the equation; $x$ is time in minutes; $y_{h}$ is temperature; $a, b$, and $c$ were constants in the sine function; $A_{3}, A_{4}, B_{k}$, and $B_{m}$ are constants in the polynomial; $k$ and $m$ are constant terms. $x_{c}$ and $y_{0}$ were the initial time and temperature of fluctuation. The initial temperatures and time of the three measuring points were $27.79{ }^{\circ} \mathrm{C}, 27.28^{\circ} \mathrm{C}$, and $26.97^{\circ} \mathrm{C}$ respectively, and the times taken were $4.17,4.18$, and $3.98 \mathrm{~min}$.

The fitting curve of case 8 was divided into two parts. The first part is the peak, which could be fitted by an eighth-order polynomial. The second part is close to a straight line, which could be fitted by a first-order function, as shown in Equation (22).

$$
y_{h}=\left\{\begin{array}{c}
A_{5}+\sum_{k} B_{k} \times x^{k} \quad x \leq x_{\text {let }} \quad k=1,2,3 \ldots 8 \\
a_{2}\left(x-x_{\text {let }}\right)+b_{2} \quad x \geq x_{\text {let }}
\end{array}\right.
$$

In the formula, $x$ is time in minutes, $y_{h}$ is temperature, $a_{2}$ and $b_{2}$ are constants in the first-order function, $A_{4}$ and $B_{k}$ are constants in the polynomial, and $k$ is the number of terms.

Case 9 could be fitted by straight lines, as shown in Equation (23).

$$
y_{h}=a_{3} x+b_{3}
$$

In the equation, $x$ is time in minutes, $y_{h}$ is temperature, and $a_{3}$ and $b_{3}$ are constants in the first order function. Table 9.

For the fitting equations (Equations (19)-(23)), the values of coefficients are shown in

The temperature distribution of the air supply and air outlet are shown in Figure 12 for the refrigeration, ventilation, and heating experiments. It can be seen in the figure that under refrigeration, the temperature difference between the air outlet and the air inlet was $8{ }^{\circ} \mathrm{C}$. The lowest temperature of the inlet was about $4^{\circ} \mathrm{C}$, and the lowest temperature of the outlet was about $12{ }^{\circ} \mathrm{C}$. In both ventilation and heating experiments, there was a small difference between the temperature of the inlet and outlet. The stable temperature was about $30^{\circ} \mathrm{C}$. When the initial temperature was set to 24 or $26^{\circ} \mathrm{C}$, the temperature of the air supply outlet rapidly reached 39 or $36^{\circ} \mathrm{C}$, and the temperature of the air outlet rapidly reached 30 or $36^{\circ} \mathrm{C}$, respectively. When refrigerating, the temperature of the air outlet can be set to about $4{ }^{\circ} \mathrm{C}$. When the set temperature was reached, the adjustment time was about 8 min intermittently. For the ventilation experiments, the air supply temperature was set to the external environment's temperature. In the heating experiments, the temperature of the air supply outlet was set to the required temperature.

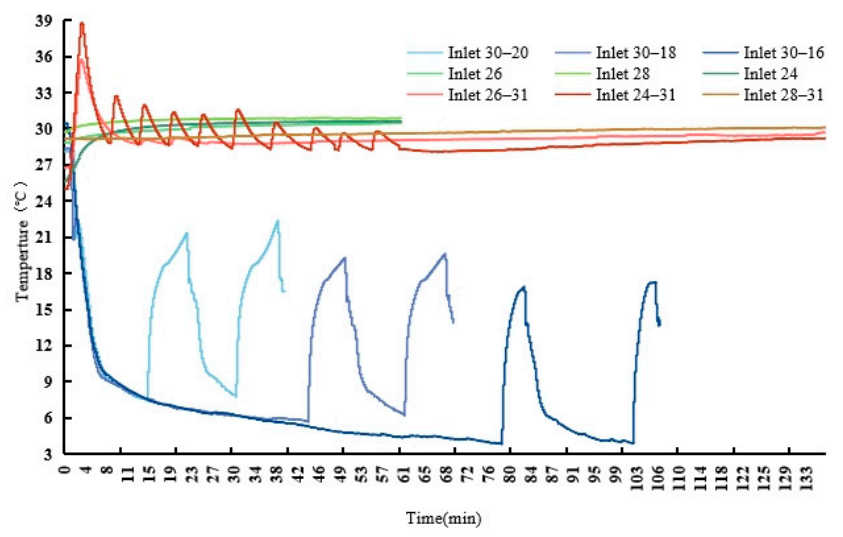

(a)

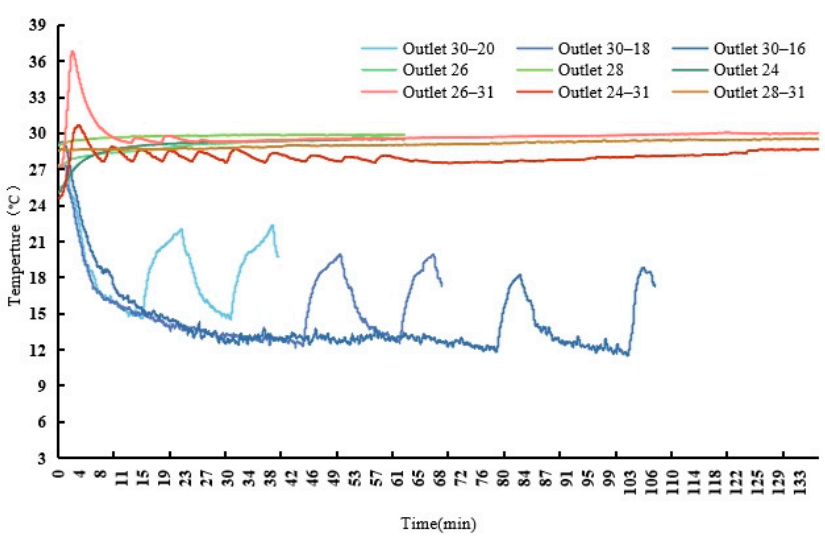

(b)

Figure 12. Average temperature distributions of the air supply and air outlet. (a) The average temperature distribution of the inlet. (b) The average temperature distribution of the outlet. 
Table 9. Coefficients of the fitting formulae in cases 1-9.

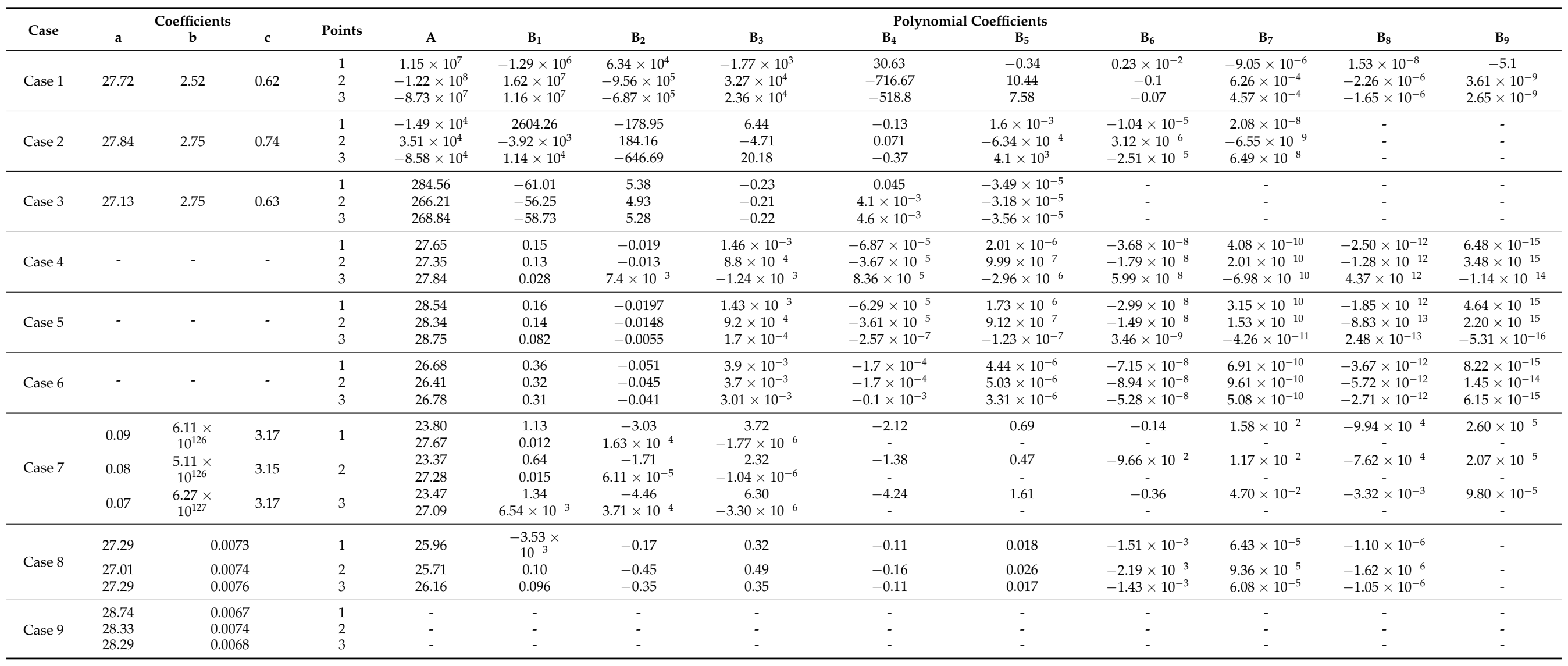




\subsubsection{Analysis of Human Body Temperature Distribution}

In the unmanned experiments, the temperatures in case 1, case 6, and case 9 remained stable for a long time. For the manned experiments, case 1, case 6, and case 9 were selected as experimental conditions for short clothing and long clothing tests. Measurement points were mostly on exposed skin in the short clothing experiments. Measurement points were mostly on the clothing and the exposed head in the long clothing experiments.

1. Data analysis of the Short clothing experiments

The temperature distribution for each measuring point on each subject is shown in Figure 13.

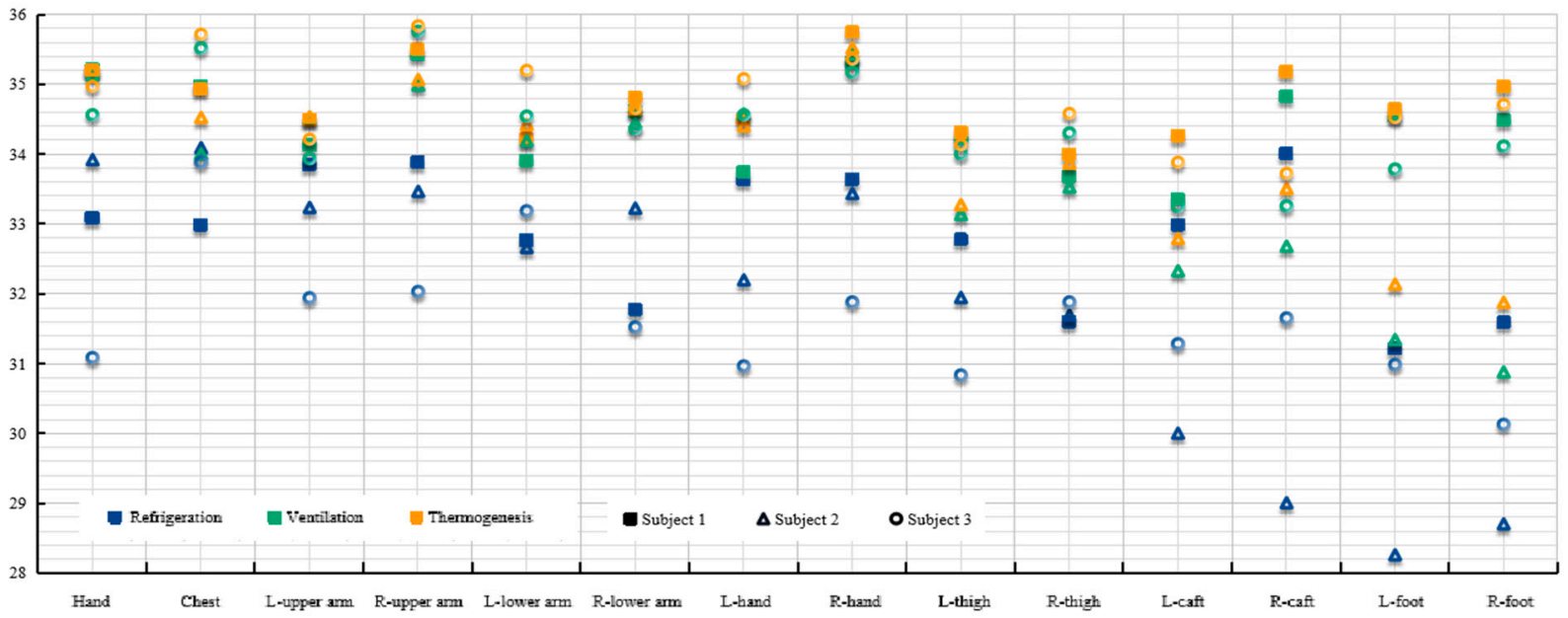

Figure 13. Temperature distributions of the three subjects wearing short clothing, at each measuring point, under three working conditions.

When a subject's data are compared for the same measuring points under different working conditions, it can be seen that the refrigeration resulted in the lowest temperature, followed by the ventilation. The temperature differences between heating and ventilated conditions were small. The average temperature differences between heating and ventilation experiments for all measuring points: subject $1-0.31{ }^{\circ} \mathrm{C}$, subject $2-0.33{ }^{\circ} \mathrm{C}$, and subject $3-0.39^{\circ} \mathrm{C}$. The average temperature differences between heating and refrigeration experiments for all measuring points: subject $1-1.93{ }^{\circ} \mathrm{C}$, subject $2-2.12{ }^{\circ} \mathrm{C}$, and subject 3-3.11 ${ }^{\circ} \mathrm{C}$.

Under the same conditions, the temperature changes of the three subjects were different. There were significant differences in skin temperature on the left and right legs and feet. Subject 2 had the lowest average temperature, followed by subject 3 . Under refrigerated conditions, subject 2 was $3.47^{\circ} \mathrm{C}$ colder than subject 1 , and subject 3 was $1.57^{\circ} \mathrm{C}$ colder than subject 1 . Under ventilated conditions, the temperature of subject 2 was $2.54{ }^{\circ} \mathrm{C}$ lower than that of subject 1 , and that of subject 3 was $0.79^{\circ} \mathrm{C}$ lower than that of subject 1 . Under heated conditions, subject 2 was $2.23^{\circ} \mathrm{C}$ colder than subject 1 , and subject 3 was $0.64{ }^{\circ} \mathrm{C}$ colder than subject 1 . However, under the refrigerated conditions, the temperatures of the head, upper arms, hands, left thighs, and right calves of subject 3 were lower than those of subjects 2 and 3 . For heating and ventilation experiments, the difference was not obvious.

The left vs. right temperature differences of the subjects under different ventilated conditions are shown in Figure 14. Under refrigeration, subject 1 had almost no obvious temperature differences between the left and right upper arms, feet, and hands; but the temperatures of the right lower arm and right thigh were more than $1{ }^{\circ} \mathrm{C}$ lower than those of their left counterparts. The temperature of the right calf was more than $1{ }^{\circ} \mathrm{C}$ higher than that of the left. In the ventilated and heated conditions, the temperature of subject 1 changed in the same way. The temperature of the right side was generally higher than that 
of the left, and the right thigh's temperature was slightly lower than that of the left; the feet showed little difference. The temperature of subject 2 was basically the same under the three conditions. The temperature decreased successively from top to bottom, and the temperature on the right side of the body was generally higher than on the left. Only under the refrigerated conditions, was the temperature of the right leg lower than that of the left. Under refrigerated conditions, the right hand was more than $1^{\circ} \mathrm{C}$ hotter than the left hand. The left calf was about $1^{\circ} \mathrm{C}$ hotter than the right one. Under ventilated conditions, the right side of the body was $0.3^{\circ} \mathrm{C}$ hotter than the left on average. Under heated conditions, the right side of the body was $0.48^{\circ} \mathrm{C}$ hotter than the left on average. Subject 3 showed great differences in skin temperature distribution concerning the left and right body parts under the three conditions. Under refrigerated conditions, the temperatures of the left hand, thigh, and calf were lower than those of the right side. The average temperature difference was $0.78{ }^{\circ} \mathrm{C}$. The left foot was hotter than the right, and the temperature difference was about $1.25^{\circ} \mathrm{C}$. Under ventilation and heated conditions, the temperature of the right upper arm was significantly higher than that of the left upper arm, and the temperature difference was more than $1.5^{\circ} \mathrm{C}$. Other temperature differences were small. The temperature of the right lower arm was slightly lower than that of the left lower arm, and the temperature of the right side of the body was slightly higher on average than that of the left. It can be seen that the temperature distributions of the subjects' bodies were not uniform in the experiment, and there were significant differences in temperature between left and right body parts.
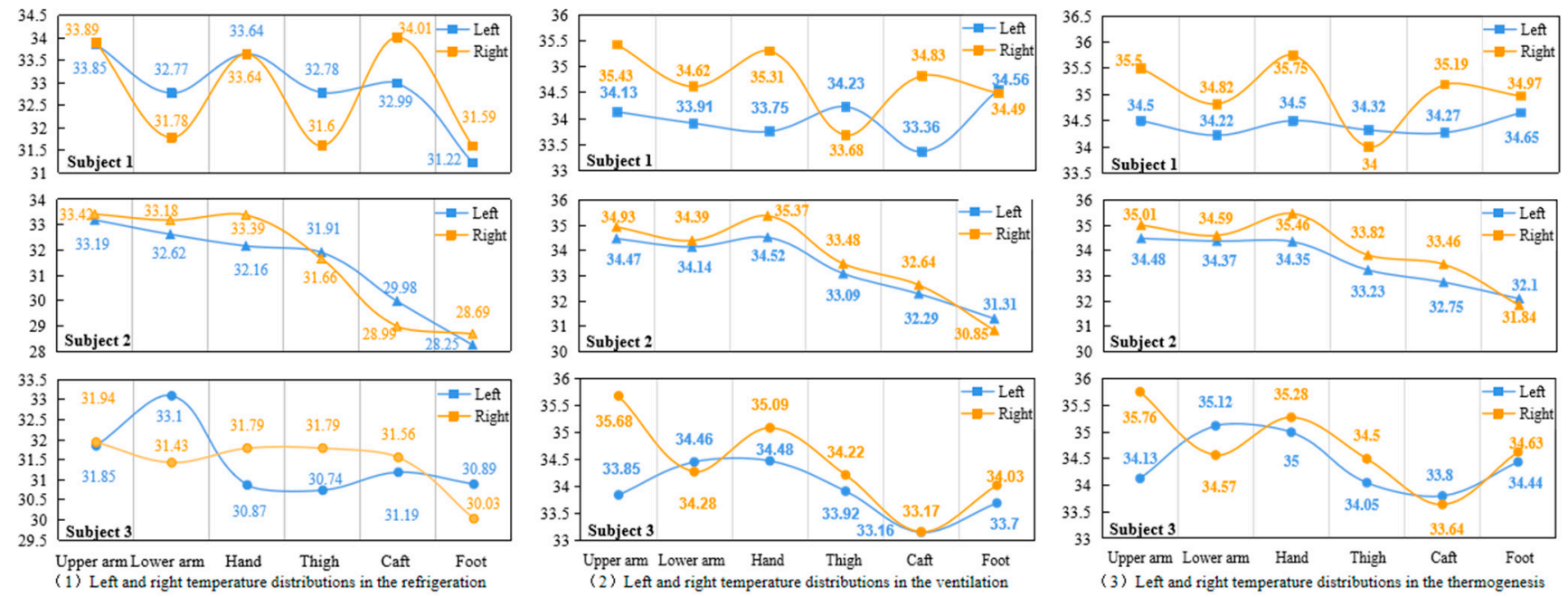

Figure 14. The temperature differences between left and right body parts were observed under different ventilated conditions wearing short clothing.

\section{Analysis of long clothing experimental data}

For the experiments with long clothing, the temperature distribution of each measuring point of each subjects under three working conditions is shown in Figure 15.

When the same subject was compared at the same measuring points under different working conditions, it was found that the refrigerated conditions caused the lowest temperature, followed by the heated conditions and the ventilated conditions. The temperature difference between heated and ventilated conditions was small. The average temperature differences between heating and ventilation experiments for all measuring points: subject $1-0.42{ }^{\circ} \mathrm{C}$, subject $2-0.74{ }^{\circ} \mathrm{C}$, and subject $3-0.55^{\circ} \mathrm{C}$. The average temperature differences between heating and refrigeration experiments for all measuring points: subject $1-2.59{ }^{\circ} \mathrm{C}$, subject $2-3.68{ }^{\circ} \mathrm{C}$, and subject $3-4.04{ }^{\circ} \mathrm{C}$. 


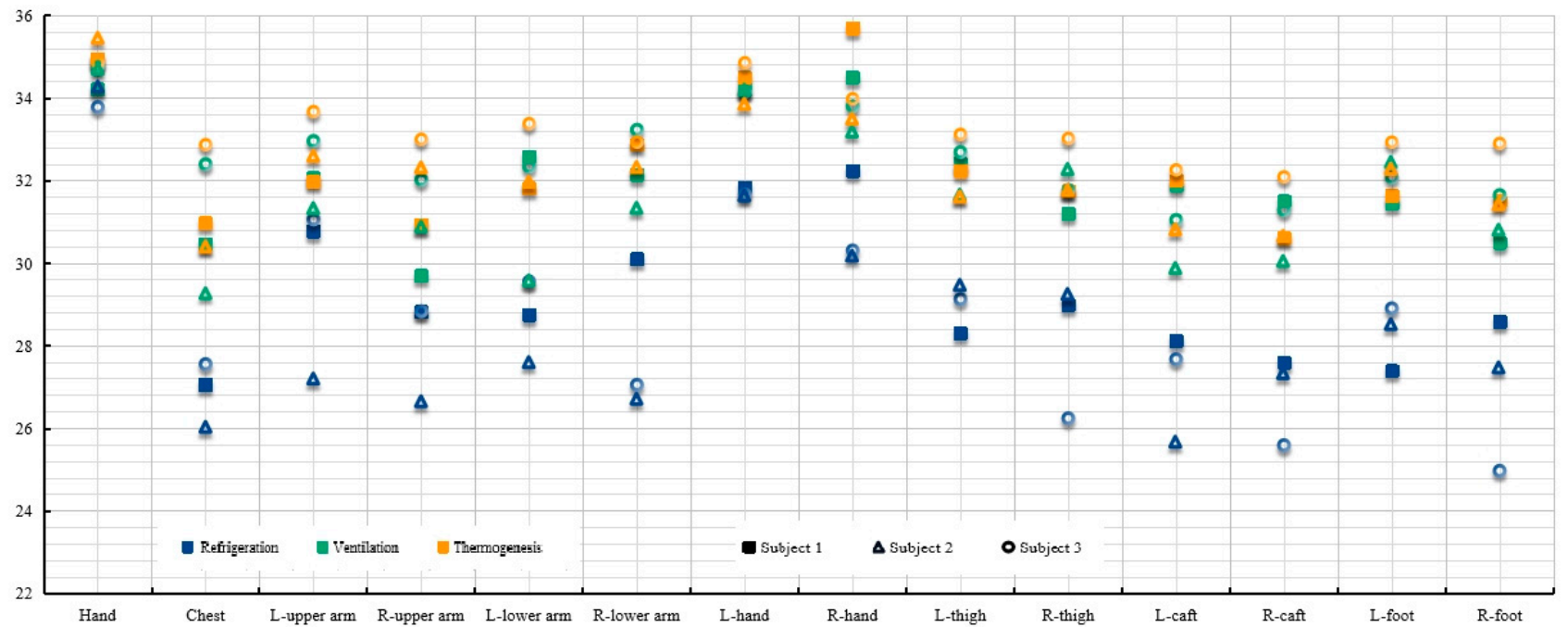

Figure 15. Temperature distribution of the three groups at each measuring point under three working conditions wearing the long clothing.

Under the same working conditions, the temperature changes of different subjects were different. The skin temperature was directly measured at the head and hands. The corresponding clothing positions were chosen as other measuring points. There was little difference between the head and hands, and the temperature of them was higher than that of parts of the clothing. Under refrigerated conditions, the head temperature of subject 1 was $6.34{ }^{\circ} \mathrm{C}$ higher than the average temperature of clothing measurement points, and the hand was $3.44^{\circ} \mathrm{C}$ higher than the average temperature clothing measurement points. The head temperature of subject 2 was $6.84{ }^{\circ} \mathrm{C}$ higher than the average temperature of the clothing measurement points, and the average hand temperature was $3.47^{\circ} \mathrm{C}$ higher than the average temperature of the clothing measurement points. The head temperature of subject 3 was $5.90{ }^{\circ} \mathrm{C}$ higher than the average temperature of the clothing measurement points, and the average hand temperature was $3.11^{\circ} \mathrm{C}$ higher than the average temperature of the clothing measurement points. Under ventilated conditions, the head temperature of subject 1 was $2.77^{\circ} \mathrm{C}$ higher than the average temperature of clothing measurement points, and the average hand temperature was $2.91^{\circ} \mathrm{C}$ higher than the average temperature of clothing measurement points. The head temperature of subject 2 was $3.84{ }^{\circ} \mathrm{C}$ higher than the average temperature of the clothing measurement points, and the average hand temperature was $2.83^{\circ} \mathrm{C}$ higher than the average temperature of the clothing measurement points. The head temperature of subject 3 was $2.63^{\circ} \mathrm{C}$ higher than the average temperature of the clothing measurement points, and the average hand temperature was $1.85^{\circ} \mathrm{C}$ higher than the average temperature of the clothing measurement points. Under the heated conditions, the head temperature of subject 1 was $2.77^{\circ} \mathrm{C}$ higher than the average temperature of clothing measurement points, and the average hand temperature was $2.91{ }^{\circ} \mathrm{C}$ higher than the average temperature of clothing measurement points. The head temperature of subject 2 was $3.84^{\circ} \mathrm{C}$ higher than the average temperature of the clothing measurement points, and the average hand temperature was $2.83^{\circ} \mathrm{C}$ higher than the average temperature of the clothing measurement points. The head temperature of subject 3 was $2.63{ }^{\circ} \mathrm{C}$ higher than the average temperature of the clothing measurement points, and the average hand temperature was $1.85{ }^{\circ} \mathrm{C}$ higher than the average temperature of the clothing measurement points.

Under the condition of refrigeration, subjects 2 and 3 were colder than subject 1 at the measuring points. Subject 2 was colder at the chest, upper arm, lower arm, and left leg. Subject 3 was colder at the right thigh, right calf, and right foot. The temperature differences between subjects 1, 2, and 3 were smaller at the other body parts. In the heated experiments, subject 2 was colder than the others in the areas of chest, left and right lower arms, left 
and right thighs, and right foot. Subject 3 was colder than the others at the left and right upper arms and left leg. There were only small differences between the temperatures of the subjects' other body parts. In the ventilation experiments, the chest, left upper arm, lower arms, calves, and thighs of subject 2 were the coldest. Subject 3 had the coldest right upper arm, right thigh, and feet. There were only small differences between the temperatures of the $1-3$ subjects' other body parts.

The left vs. right temperature differences of subjects under different ventilated conditions are shown in Figure 16. The differences between the left and right sides of the upper arms, the lower arms, and the feet were obvious under the refrigerated conditions. The temperature of the left upper arm was more than $1.95^{\circ} \mathrm{C}$ higher than that of the right, and the temperatures of the right lower arm and the right foot were $1.35{ }^{\circ} \mathrm{C}$ and $1.2{ }^{\circ} \mathrm{C}$ higher than the left of the same. The temperature differences between hands, thighs, and legs were less than $0.5^{\circ} \mathrm{C}$. Under ventilated conditions, the temperature on the left side of subject 1 was generally higher than the right side, and the temperature differences between the left and right upper arms, thighs, and feet were large-about $2.36{ }^{\circ} \mathrm{C}, 1.22{ }^{\circ} \mathrm{C}$, and $0.95{ }^{\circ} \mathrm{C}$, respectively. Under heated conditions, the left upper arm and lower leg were $1.05^{\circ} \mathrm{C}$ and $1.39{ }^{\circ} \mathrm{C}$ hotter than the right of the same. The right lower arm and hand were hotter than the left; the temperature differences were $1.05^{\circ} \mathrm{C}$ and $1.2^{\circ} \mathrm{C}$, respectively.
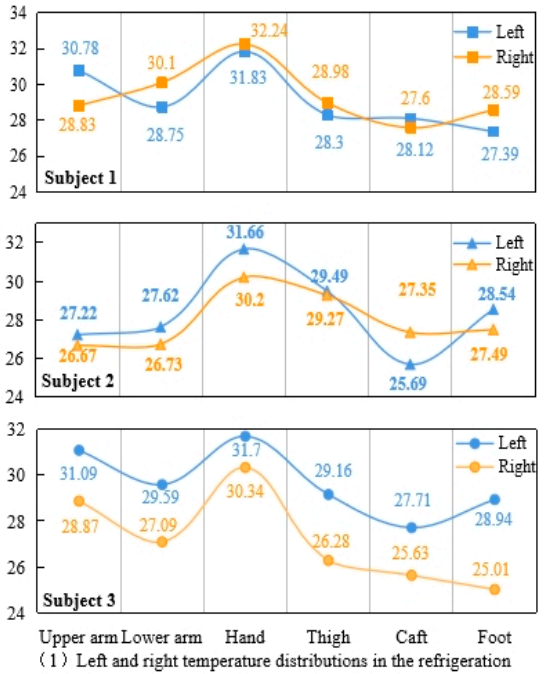
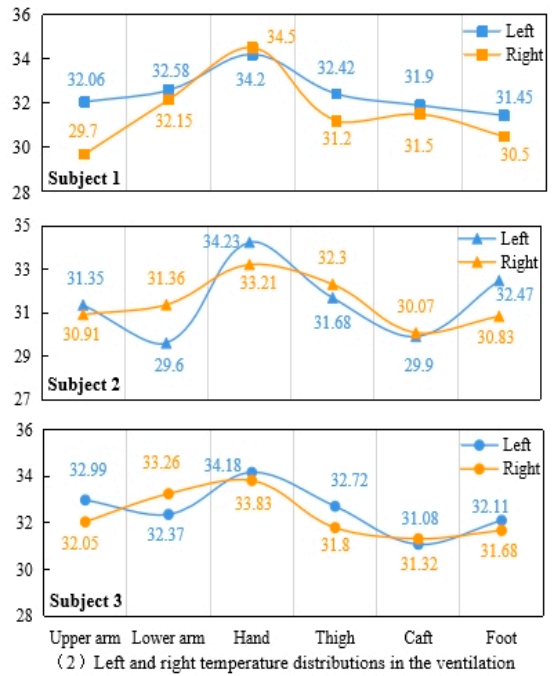
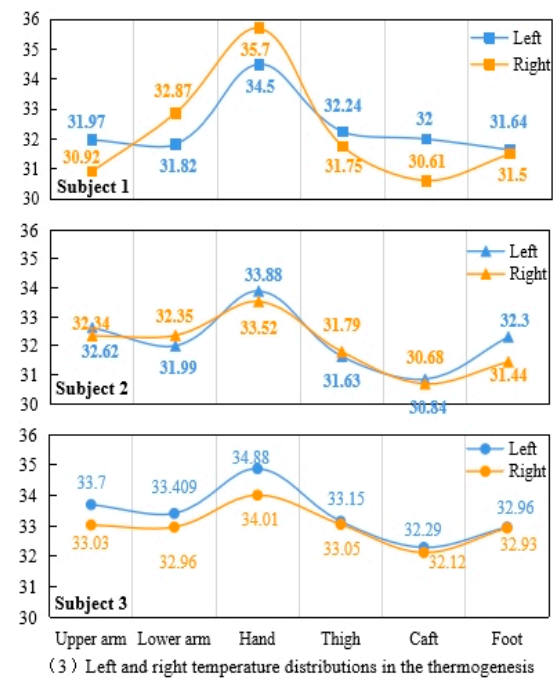

Figure 16. The temperature differences between left and right body parts observed under different ventilated conditions while wearing long clothing.

Subject 2: In refrigerated conditions, the temperature of the left side of the body was significantly higher than the right, except that the temperature of the right calf was $1.66{ }^{\circ} \mathrm{C}$ higher than the left. Under ventilated conditions, the temperature of the right lower arm was higher than the left, with a temperature difference of $1.76{ }^{\circ} \mathrm{C}$. The left hand and foot were hotter than the right, with temperature differences of more than $1{ }^{\circ} \mathrm{C}$. Under heated conditions, the left foot was hotter than the right; the temperature difference was about $0.86{ }^{\circ} \mathrm{C}$. The other temperature differences were smaller. In the refrigerated conditions, for subject 3 , the temperature on the left side of the body was significantly higher than on the right side, and the temperature difference ranged from 1.36 to $3.93{ }^{\circ} \mathrm{C}$. In the cases of ventilation and heating, the temperature differences between corresponding parts were small; the average temperature difference did not exceed $0.5^{\circ} \mathrm{C}$. Therefore, in the experiment, the temperature distribution of each part of the human body when wearing long clothing was not uniform, and there were significant temperature differences between the left and right parts.

The temperature differences can be explained. The air supply temperature differences reflect the differences between subjects. Subject 2's legs and feet were colder under three ventilation temperatures than those of subjects 1 and 3, which can be seen in Figures 9-11, 
and later can be seen in the temperature distribution of measuring points. The temperature of measuring point 2 is the green curve in each graph, which is always slightly lower than any other curve in temperature. At the same time, the wind speeds around subject 2 and 3 were also lower than that around subject 1 . The combined effect of low temperature and low wind speed made subject 2 have the coldest legs and feet, followed by subject 3. As shown in Figure 12, the wind passing through the air inlet directly blew toward the upper body of subject 3 , so his head, upper arm, and hand were significantly colder than those of subject 2 and 1.

There were temperature difference for the same subject under different air supply conditions. The wind speed of the air inlet was relatively high, and the wind speed directly opposite the air inlet was measured at about $8 \mathrm{~m} / \mathrm{s}$. Under refrigerated conditions, the air supply rapidly blew cold air from the air inlet to the upper bodies of the three groups of subjects through the top of the chamber. Therefore, the air temperature difference in the space around the heads and upper arms of the subjects was small and the wind speed changed little, so the temperature differences between left and right body parts were small. However, the lower arms, trunk, and thighs did not receive wind at a high speed to reduce the temperature of the surrounding air, so the temperatures of these parts of the body experienced a ladder of temperature transmission - that is, the temperatures of the right sides of their bodies were lower than those of their left sides. The air flow above the upper arm of subject 1 would flow through the calf. Although there was little difference in air flow temperature, subject 1's calf temperature was not only affected by ambient air temperature, but also by wind speed because subject 1 was wearing short clothing. At this time, the wind speed on the left side was higher, so the temperature of the left leg should have been lower than that of the right. Subject 1's feet had socks to block the wind, so their temperature did not change much. The temperature differences at the middle parts of the two subjects were clear: the temperature of the left leg was higher than that of the right leg. The three subjects could not have air blown to their right, so most of the temperatures on the left side of the body were lower than those on the right. Under ventilation and heating conditions, the temperature of the air supply outlet was higher than that of the cabin, and when the temperature was higher, the wind had little means of reducing human body temperature. Therefore, the temperature on the right side of the whole cabin was higher than that on the left side. Therefore, the temperatures on the right sides of the three groups were generally higher than on their left sides under these two air supply conditions.

Interpretation of different temperature distributions when wearing normal clothes and short clothes: When the subjects were wearing normal clothes, the distribution law of human skin temperature measured directly was the same as that when wearing short-sleeved shirts and shorts, but there were great differences between the measured outer points of normal clothes and skin. The temperature measured at this time was the temperature of the combined action of the human body and air. It was less affected by wind speed and mainly affected by cabin temperature distribution. Under refrigerated conditions, the cabin temperature was lower on the left side of subject 2 and the right side of subject 3 . Under ventilation and heated conditions, the overall temperature on the right side of each subject was slightly higher than that on the left side. The wind brought the warm air to the left side of subject 1 , so the temperatures on the left side of subject 1 were significantly higher than those on the right side.

\section{Analysis of temperature difference of humans wearing different clothes}

Through the experiments with long and short clothing, we knew that the temperatures of left and right body parts and higher and lower body parts varied. Location, ventilated conditions, clothing, and measuring points were analyzed for the human left vs. right side temperature difference.

The influences of location, ventilated conditions, clothing, and measuring point locations on the bodily temperature distribution were analyzed. Firstly, one-way ANOVA showed that the location factor had no significant effect on the human temperature distribution, whereas clothing selection, air supply conditions, and measuring points had 
significant effects on the temperature of the humans. Secondly, it can be seen from the multivariate ANOVA that there were significant differences between two groups of factors: wind supply conditions and clothing selection, and the locations of measurement points and clothing selection. The multi-factor ANOVA is shown in Figure 17. At last, the influences of the above factors on the temperature distribution and the temperature differences between left and right body parts should be considered in the simulation of the thermal environment in the shelter.

\begin{tabular}{|c|c|c|c|c|}
\hline L-R Different & Clothing & Condition & Human points & L-R temperature \\
\hline \multicolumn{5}{|c|}{ Temperature } \\
\hline \multirow[t]{2}{*}{ Clothing } & $1.39 \times 10^{-35}$ & \multirow[t]{2}{*}{$1.02 \times 10^{-4}$} & \multirow[t]{2}{*}{$1.60 \times 10^{-5}$} & \multirow{2}{*}{$3.90 \times 10^{-3}$} \\
\hline & $4.97 \times 10^{-36}$ & & & \\
\hline \multirow{2}{*}{ Condition } & & $2.80 \times 10^{-42}$ & \multirow[b]{2}{*}{0.637} & \multirow[b]{2}{*}{0.17} \\
\hline & $5.77 \times 10^{-5}$ & $1.78 \times 10^{-42}$ & & \\
\hline \multirow{2}{*}{ Human points } & & & $1.38 \times 10^{-18}$ & \multirow[b]{2}{*}{0.77} \\
\hline & $9.2 \times 10^{-6}$ & 0.90 & $6.15 \times 10^{-16}$ & \\
\hline \multirow[t]{2}{*}{ L-R temperature } & & & & $0.5 \times 10^{-2}$ \\
\hline & - & - & - & - \\
\hline
\end{tabular}

Figure 17. The multi-factor ANOVA on the temperature distribution and difference between left and right.

\subsection{Analysis the Wind Speed at the Measuring Points}

\subsubsection{Distribution of Average Wind Speed at Each Measuring Point of Air Supply Pipeline}

The temperature of the air at each measuring point remained basically unchanged, but the velocity was changed. The wind speed at points 6 and 7 (air supply) was higher than $4 \mathrm{~m} / \mathrm{s}$. Due to the loss of the wind velocity at the corner, the velocity at measuring points $1-5$ was less than $2 \mathrm{~m} / \mathrm{s}$. It was gradually increasing at points $1-4$. The wind at point 5 point was slower than at point 4 . As can be seen in Figure 18, the wind speed distribution was uneven in the shelter. At the same time, it can be seen that the wind speed of each air supply inlet under refrigerated conditions was significantly greater than under ventilation and heated conditions.

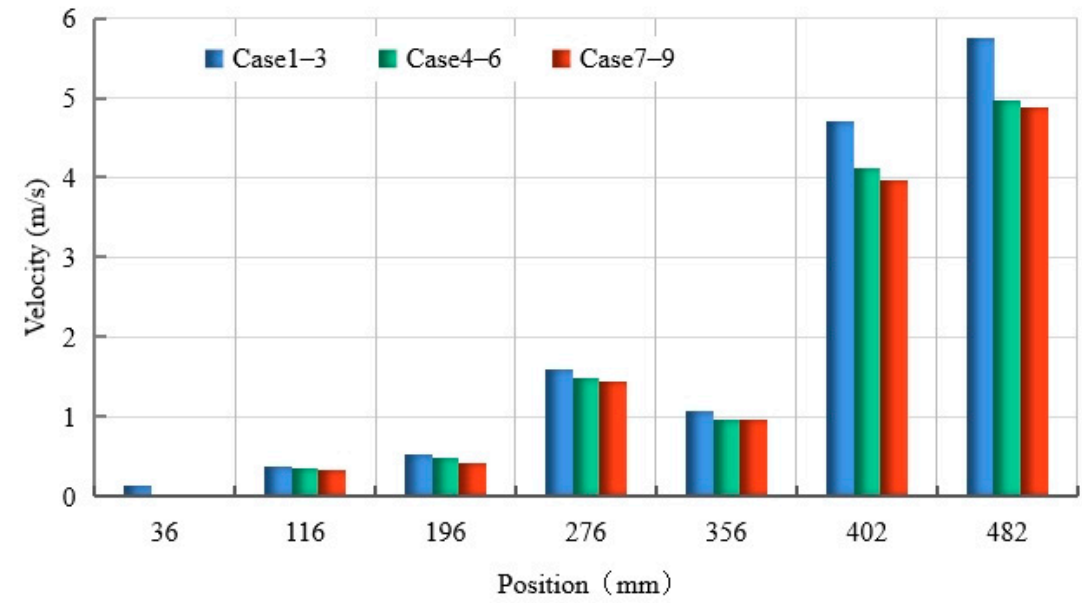

Figure 18. Location and wind speed distribution sequence of monitoring points.

The reasons for the difference in wind speed were as follows:

The volume flux of the gas was constant. When the gas entered the pipe, the volume did not change quickly. In the refrigerated conditions, the air supply temperature was low. 
According to the ideal gas equation of state as Equation (24), when a low temperature gas meets a high temperature gas, the temperature will rise suddenly, resulting in an instant increase in pressure, which generates a larger driving force along the direction of fluid movement and increases the wind speed.

$$
\frac{P_{0} V_{0}}{T_{0}}=\frac{P_{1} V_{0}}{T_{1}}
$$

At the corner, the driving force was weakened. When the wind reached measuring points $1-5$, the wind speed decreased obviously. However, under heating and ventilated conditions, the air supply temperature was slightly higher than the temperature in the pipe, resulting in an instant drop in pressure. Thus, the wind speed decreased, but the overall change was small.

\subsubsection{Analysis of Wind Speed Distribution in Special Sections}

The wind speed distributions (cloud diagrams) on surface 4 of the manned and unmanned thermal environments are shown in Figure 19. The air flow was ejected through the inlet in the form of jet flow, and the adhesive air flow was formed on the upper wall and side wall. Due to the action of adhesion force, the air flowed to the left side of the shelter, and began to sink and flow back to the air outlet. In the unmanned experiment, the wind speed of surface 4 was generally above $0.4 \mathrm{~m} / \mathrm{s}$, and the distribution was not uniform. The wind speed near the air supply outlet and inlet was larger than that far from the tuyeres. In the manned experiment, the average vertical temperature difference of a human reached about $4.5^{\circ} \mathrm{C}$. Due to the thermal convection caused by the temperature difference, a rising thermal plume was formed around each human body. The temperatures in those areas were higher than that of mechanical air flow, so the mixing of the two weakened the adhesion of jet and increased the confusion of air flow in the shelter. As can be seen in Figure 19b, the overall wind speed decreased, and the portion greater than $0.7 \mathrm{~m} / \mathrm{s}$ decreased compared with the unmanned experiment. The air flow around the human body was generally between 0.5 and $0.3 \mathrm{~m} / \mathrm{s}$, but the distribution was still not uniform.

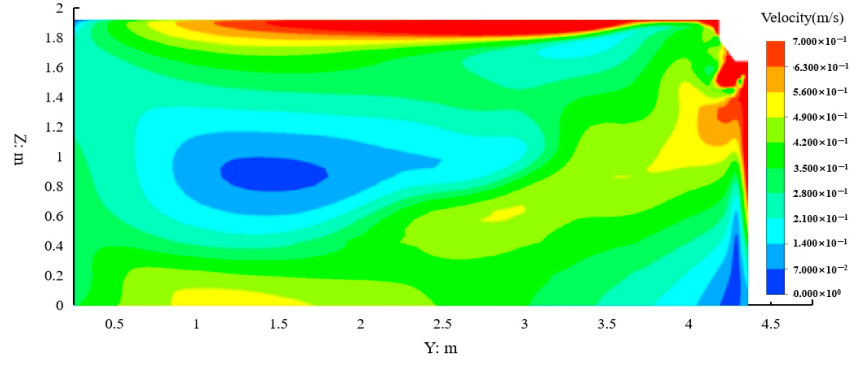

(a)

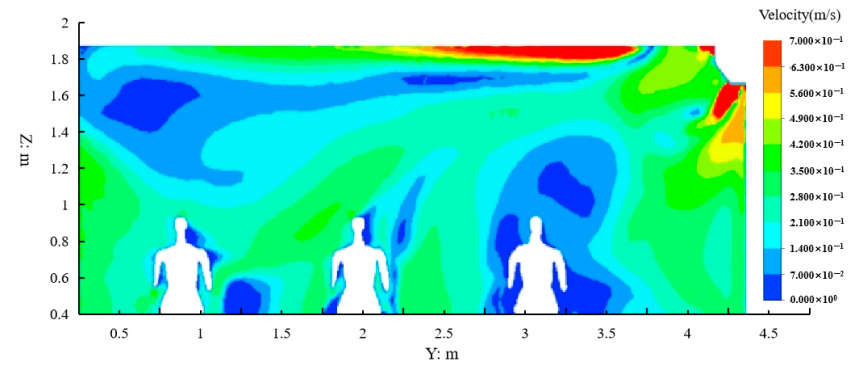

(b)

Figure 19. Cloud image of wind speed distribution in manned/unmanned shelter. (a) Air velocity of unmanned, (b) Air velocity of manned.

The velocity vector of surface 4 is shown in Figure 20. In the unmanned cabin experiment, the air flow was ejected by the air supply vent in the form of jet, forming attached air flow on the ceiling; then flowed rapidly to the back wall, forming a whirlpool on the upper part of the latter half of the cabin, and finally flowing to the air outlet through the floor. In the manned cabin experiment, the jet flow through the air supply interacted with the thermal plume generated by the human body, resulting in a decrease in the overall velocity. The air flowed from the inlet to the back wall and formed a vortex at the head of subject 3. A part of the air flowed upward past subject 2 toward the air outlet, and the other part flowed toward the air outlet from the ground around subject 3 . It can be seen that the human thermal plume had a great influence on the air distribution in the shelter. Although the wind speed was reduced, the flow of air distribution was more complex and uneven. 
The cloud and vector distributions in surface 1-3 are shown in Figure 21. In the unmanned experiment, surface 1 was close to the inlet, and the adsorbed air flow velocity on the ceiling was large, which collided with the air flow with lower velocity on the side wall air outlet and formed a vortex. As the jet velocity of the inlet at surface 1 was large, it was difficult for the air flowing out of the side wall outlet to reach the left wall. When the jet flow from the inlet reached surface 2, the wind speed decreased, and that air mixed with the air from the side wall's air outlet. Then, some air flowed to the left wall, increasing the wind speed of the left wall. When the jet reached surface 3 , the wind speed decreased significantly, and at this time, it was fully mixed with the wind of the side air supply outlet and flowed to the left wall. The wind speed of the left wall increased significantly, and the area with high wind speed increased.

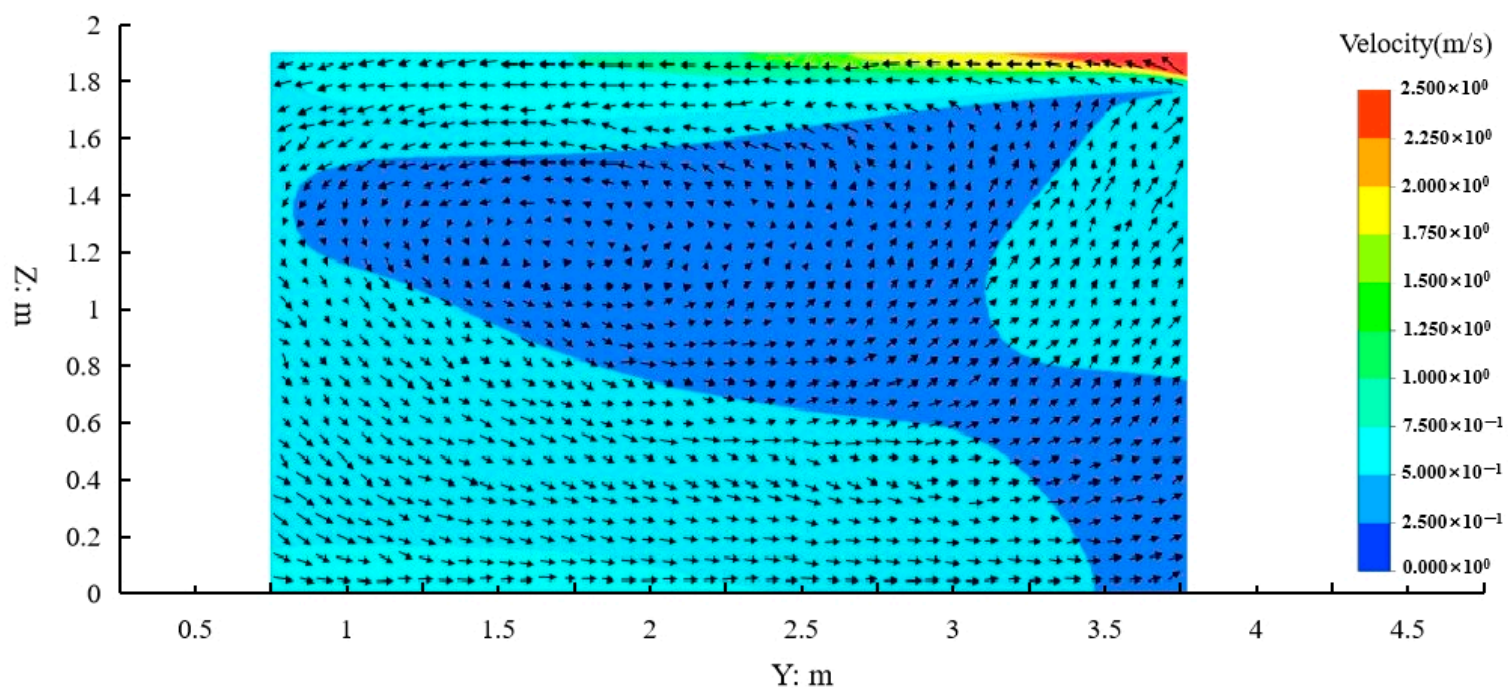

(a)

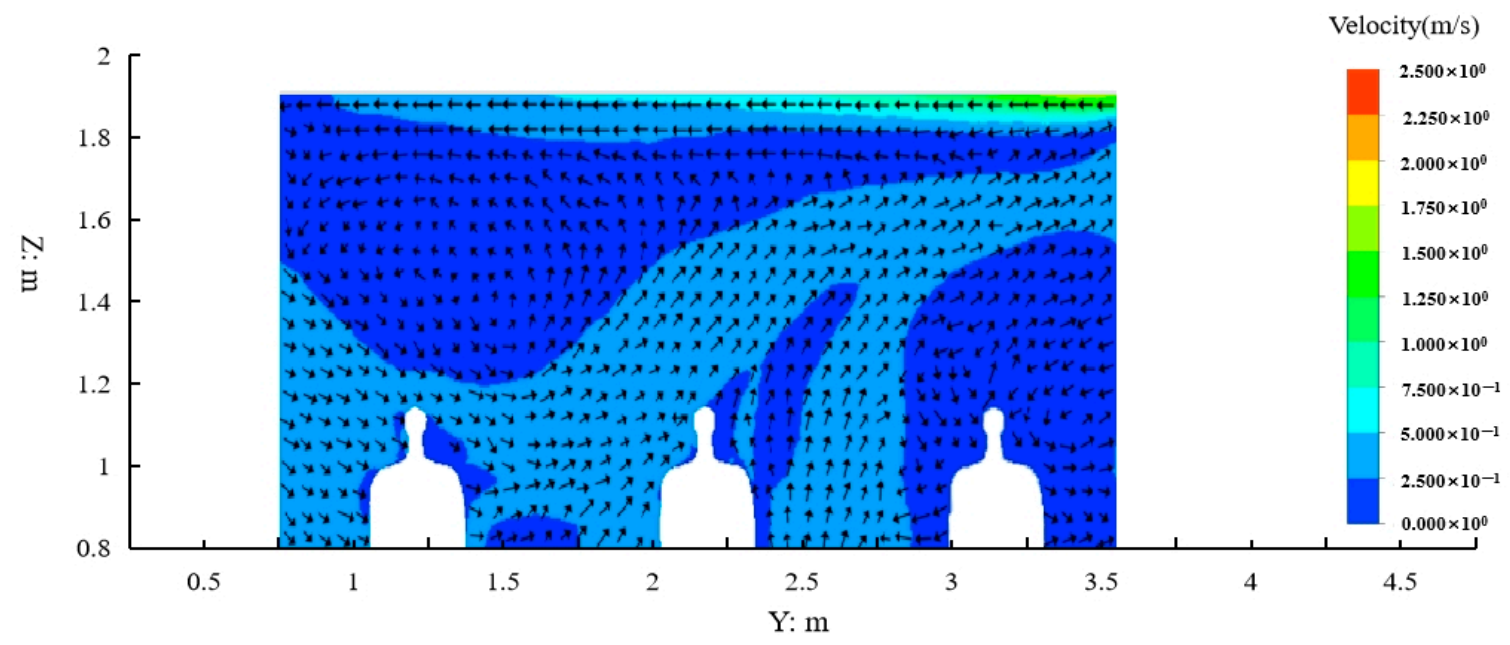

(b)

Figure 20. Vector diagrams of wind speed distribution in manned/unmanned shelters. (a) Vector diagram of surface 4 in the unmanned shelter. (b) Vector diagram of surface 4 in a manned shelter.

In the manned experiment, the mixing of jet and thermal plumes caused by human thermal convection weakened the adsorption effect. At surface 1, the air from the side air supply outlet was mixed with the air flow from the inlet and flowed to the left wall. The jet was obviously weakened, and the air flow from the left wall was larger than in 
the unmanned cabin. The air flow from the inlets on surfaces 2 and 3 also weakened significantly, and the place where the wind speed was high moved to the left, closer to the left wall. The updraft produced by the human body was mixed with the downdraft from the side air outlet, forming a vortex at the oblique top of the subjects' heads. It can be seen that the thermal plume generated by humans due to temperature had a great influence on the air distribution in the shelter, which is consistent with the research conclusion of Cao [15].

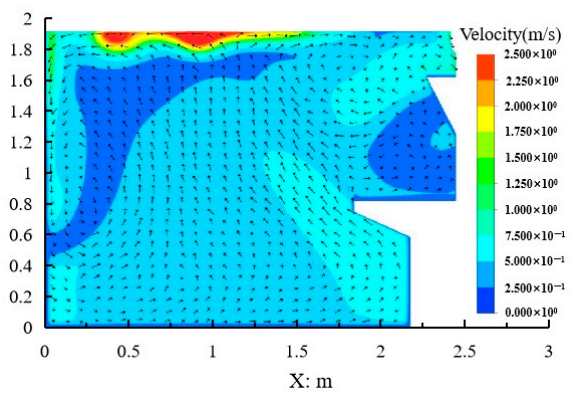

(a)

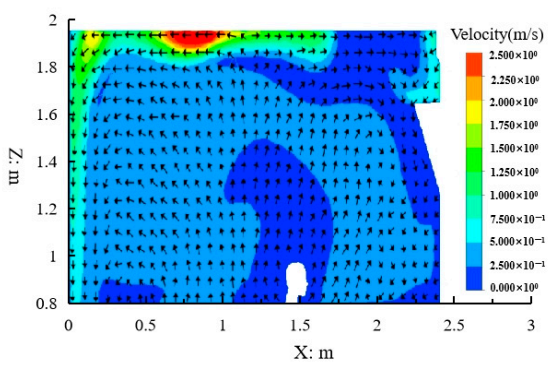

(d)

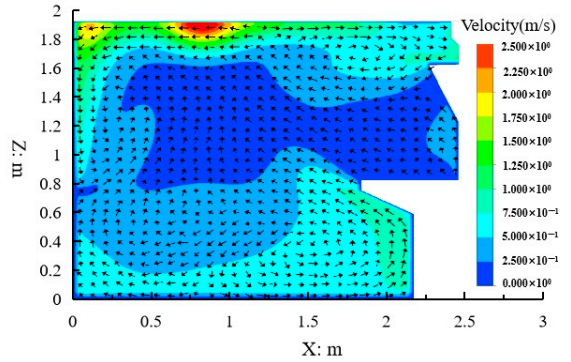

(b)

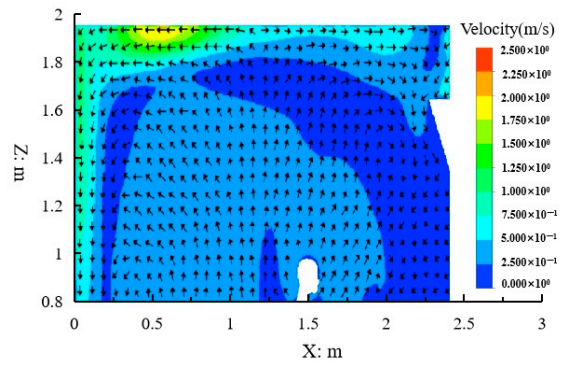

(e)

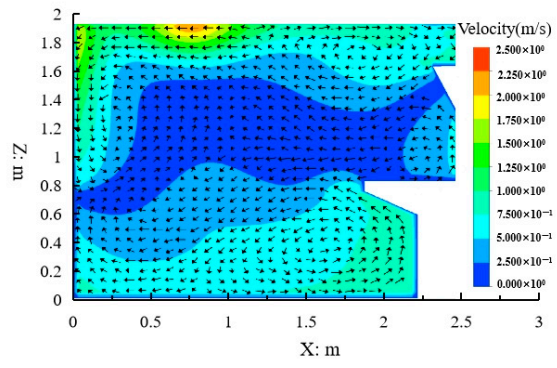

(c)

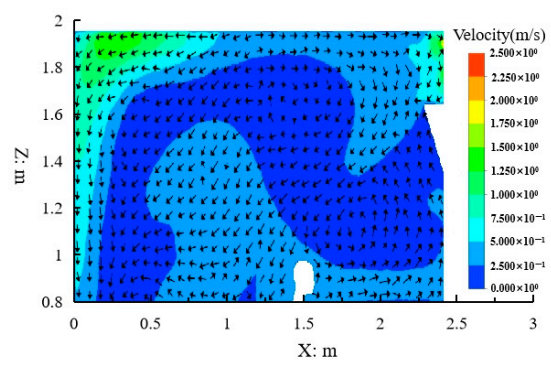

(f)

Figure 21. Split diagram of speed vector for manned/unmanned experiments. (a) Surface 1 of unmanned; (b) surface 2 of unmanned; (c) surface 3 of unmanned; (d) surface 1 of manned; (e) surface 2 of manned; (f) surface 3 of manned.

\section{Conclusions}

In this paper, a comparative study of manned and unmanned shelters was carried out for a special indoor environment. The air temperature and velocity were measured at various points. In the unmanned experiment, temperature and velocity at each measuring point under different air supply conditions were mainly compared. In the manned experiment, temperature differences between short and long clothing were mainly compared. Finally, the distributions of air velocity in manned/unmanned experiment were compared. The study results can be summarized into the following four points.

1. The measured values of wind velocity and temperature in the experiment can provide experimental verification of initial and wall conditions and simulation results for shelter simulation.

2. The function fitted from the experimental data of temperature distribution in the shelter can provide the control equations for the study of air flow temperature control.

3. Different wearing conditions, air supply conditions, body part temperatures, and temperature differences between coinciding left and right body parts should be taken into account in a simulation model.

4. The thermal plume caused by the vertical temperature difference of the human body has a certain influence on the air distribution in the shelter, which should be paid attention to and taken into account in simulations. 
Author Contributions: Conceptualization, H.X. and Y.C.; methodology, J.Q.; software, H.G.; data curation, S.D.; validation, S.D., J.Q. and H.G.; formal analysis, J.Q.; investigation, J.Q.; resources, J.Q.; data curation, S.D.; writing—original draft preparation, J.Q.; writing—review and editing, S.D.; visualization, H.X.; supervision, Y.C.; project administration, H.X.; funding acquisition, H.X. and J.Q. All authors have read and agreed to the published version of the manuscript.

Funding: This research received no external funding.

Institutional Review Board Statement: Ethical review and approval were waived for this study due to REASON (The instrument only measures the external skin temperature of the human body and has no impact on the physical and mental health of the human body. The equipment does not have any bad effect, and contact with human parts will not cause harm to human body).

Informed Consent Statement: Informed consent was obtained from all subjects involved in the study.

Data Availability Statement: The data presented in this study are available on request from the corresponding author. The data are not publicly available due to some data involve detailed equipment parameters, these parameters cannot be disclosed.

Acknowledgments: The research was supported by the National Natural Science Foundation of China (grant number 52,175,282 and 51,975,477).

Conflicts of Interest: The authors declare no conflict of interest.

\section{References}

1. Zhang, M.L.; Jiang, M.; Huang, Y. Simulation Study of Thermal Environment in an Electronic Shelter. Equip. Environ. Eng. 2018, 15, 5-9.

2. Zhao, W.; Shi, T.; Zhu, C.; Chen, S.; Han, Y. Design of Air Conditioning System for a Radar Cabin Based on Human Thermal Comfort. Electro-Mech. Eng. 2020, 36, 46-49.

3. Qi, L.; Liu, J.; Zhang, L.; Wu, Q. Study on local thermal sensation and model applicability in vehicle cabin under different driving states. Heat Mass Transf. 2021, 57, 41-52. [CrossRef]

4. Li, J.; Liu, J.; Dai, S.; Guo, Y.; Jiang, N.; Yang, W. PIV experimental research on gasper jets interacting with the main ventilation in an aircraft cabin. Build. Environ. 2018, 138, 149-159. [CrossRef]

5. Yang, Z.; Fei, J.; Song, D.; Zhao, Y.; Yu, J.; Yu, X. Effects of simulated natural air movement on thermoregulatory response during head-down bed rest. J. Therm. Biol. 2013, 38, 363-368. [CrossRef]

6. Gilani, S.; Montazeri, H.; Blocken, B. CFD simulation of stratified indoor environment in displacement ventilation: Validation and sensitivity analysis. Build. Environ. 2016, 95, 299-313. [CrossRef]

7. Liu, W.; Mazumdar, S.; Zhang, Z.; Poussou, S.B.; Liu, J.; Lin, C.H.; Chen, Q. State-of-the-art methods for studying air distributions in commercial airliner cabins. Build. Environ. 2012, 47, 5-12. [CrossRef]

8. Fujita, A.; Kanemaru, J.I.; Nakagawa, H.; Ozeki, Y. Numerical simulation method to predict the thermal environment inside a car cabin. JSAE Rev. 2001, 22, 39-47. [CrossRef]

9. Ware, Y.A.; Khalighi, B. Data-driven prediction of vehicle cabin thermal comfort: Using machine learning and high-fidelity simulation results. Int. J. Heat Mass Transf. 2020, 148, 1-12. [CrossRef]

10. Zhang, T.F.; Chen, Q. Novel air distribution systems for commercial aircraft cabins. Build. Environ. 2007, 42, 1675-1684. [CrossRef]

11. Lu, W.; Huang, J.R.; Fan, Y.F.; Zhong, Q. Numerical Model of Flow and Heat Transfer for Manned Spacecraft Pressurized Cabin and Its Ground Verification. J. Astronaut. 2011, 32, 959-965.

12. Awolesi, S.T.; Awbi, H.B.; Seymour, M.J.; Hiley, R.A. The use of CFD techniques for the assessment and improvement of a workshop ventilation system. In IMechE Seminar on CFD-Tool or Toy; Pergamon Press Ltd.: London, UK, 1991 ; pp. $39-46$.

13. Zhang, W.; Chen, J.; Lan, F. Experimental study on occupant's thermal responses under the non-uniform conditions in vehicle cabin during the heating period. Chin. J. Mech. Eng. 2014, 27, 331-339. [CrossRef]

14. Chai, Y.; Li, W.; Liu, Z. Analysis of transient wave propagation dynamics using the enriched finite element method with interpolation cover functions. Appl. Math. Comput. 2022, 412, 126564. [CrossRef]

15. Cao, X.; Li, J.; Liu, J.; Yang, W. 2D-PIV measurement of isothermal air jets from a multi-slot diffuser in aircraft cabin environment. Build. Environ. 2016, 99, 44-58. [CrossRef]

16. Li, J.; Liu, J.; Cao, X.; Jiang, N. Experimental study of transient air distribution of a jet collision region in an aircraft cabin mock-up. Energy Build. 2016, 127, 786-793. [CrossRef]

17. Li, F.; Liu, J.; Pei, J.; Lin, C.H.; Chen, Q. Experimental study of gaseous and particulate contaminants distribution in an aircraft cabin. Atmos. Environ. 2014, 85, 223-233. [CrossRef]

18. Li, Z.; Guan, J.; Yang, X.; Lin, C.H. Source apportionment of airborne particles in commercial aircraft cabin environment: Contributions from outside and inside of cabin. Atmos. Environ. 2014, 89, 119-128. [CrossRef]

19. Zhang, Y.; Liu, J.; Pei, J.; Li, J.; Wang, C. Performance evaluation of different air distribution systems in an aircraft cabin mockup. Aerosp. Sci. Technol. 2017, 70, 359-366. [CrossRef] 
20. Yang, Z.; Fei, J.; Yu, X. Thermal Comfort and Thermoregulation in Manned Space Flight. Chin. J. Appl. Physiol. 2013, 29, 518-524.

21. Mao, Y.; Wang, J.; Li, J. Experimental and numerical study of air flow and temperature variations in an electric vehicle cabin during refrigeration and heating. Appl. Therm. Eng. 2018, 137, 356-367. [CrossRef]

22. Aboosaidi, F.; Warfield, M.J.; Choudhury, D. Numerical analysis of airflow in aircraft cabins. In Proceedings of the 21st International Conference on Environmental Systems, San Francisco, CA, USA, 15-18 July 1991; pp. 1441-1446.

23. Meng, F.; Man, G.; Cao, J. A simplified manned spacecraft cabin air temperature control model and its verification. In Proceedings of the 42nd International Conference on Environmental Systems, San Diego, CA, USA, 15-19 July 2012.

24. Han, D.; Li, R.; Wang, F.; Sun, Z.; Moon, S.; Gong, Z.; Yu, W.; Zhang, Y. Study on Indoor Thermal Environment Control Based on Thermal Sensation Prediction. Procedia Eng. 2017, 205, 3072-3079. [CrossRef]

25. Li, Y.; Wei, Q. Simulation of Thermal Environment in Shelter. Electro-Mech. Eng. 2010, 26, 8-9, 21.

26. Liu, X.H.; Yang, J.Z.; Zhang, Y.T.; Xia, L.N. Simulation Analysis of Thermal Environment in a Radar Shelter. Electro-Mech. Eng. 2012, 28, 8-14.

27. Li, W.Z. Thermal Design of Electronic Shelter Using ICEPAK Software. Radio Eng. 2011, 41, 55-61.

28. Mao, Q.J.; Yong-Qing, J.I.; Yun, J.I. Thermal Analysis of Electronic Equipment Shelter. Electro-Mech. Eng. 2014, $30,24-26$.

29. Pei, D.D. Design Method for Environment Control of Electronic Square Cabin. Movable Power Stn. Veh. $2012,2,10-12$.

30. Feng, S.X.; Wang, S.; Yue, W.Q.; Tan, G.B. Research on Heat Transfer Test Method of Shelter. Equip. Environ. Eng. $2011,8,109-111$.

31. Liao, C.Y.; Chen, S.L.; Chou, T.D.; Lee, T.P.; Dai, N.T.; Chen, T.M. Use of two-dimensional projection for estimating hand surface area of Chinese adults. Burns 2008, 34, 556-559. [CrossRef] 